\title{
Spatial and Temporal Characteristics of Precipitation and Potential Influencing Factors in the Loess Plateau before and after the Implementation of the Grain for Green Project
}

\author{
Jichao Wang ${ }^{1}$, Miao Sun ${ }^{1}$, Xuerui Gao ${ }^{2, *}$, Xining Zhao ${ }^{2, *}$ and Yong Zhao ${ }^{3}[$ \\ 1 College of Water Resources and Architectural Engineering, Northwest A\&F University, \\ Yangling 712100, China; wangjichao0208@163.com (J.W.); sunmiao19930526@163.com (M.S.) \\ 2 Institute of Soil and Water Conservation, Northwest A\&F University, Yangling 712100, China \\ 3 State Key Laboratory of Simulation and Regulation of Water Cycle in River Basin, \\ China Institute of Water Resources and Hydropower Research, Beijing 100038, China; zhaoyong@iwhr.com \\ * Correspondence: gaoxr@nwsuaf.edu.cn (X.G.); zxn@nwsuaf.edu.cn (X.Z.)
}

Citation: Wang, J.; Sun, M.; Gao, X.; Zhao, X.; Zhao, Y. Spatial and Temporal Characteristics of Precipitation and Potential Influencing Factors in the Loess Plateau before and after the Implementation of the Grain for Green Project. Water 2021, 13, 234. https://doi.org/10.3390/w13020234

Academic Editor: Momcilo Markus Received: 19 October 2020

Accepted: 17 January 2021

Published: 19 January 2021

Publisher's Note: MDPI stays neutral with regard to jurisdictional claims in published maps and institutional affiliations.

Copyright: (c) 2021 by the authors. Licensee MDPI, Basel, Switzerland. This article is an open access article distributed under the terms and conditions of the Creative Commons Attribution (CC BY) license (https:// creativecommons.org/licenses/by/ $4.0 /)$.

\begin{abstract}
Since the implementation of the Grain for Green Project (GFGP) in the 1990s, the warming and wetting trend in the Loess Plateau is becoming statistically significant in the context of climate change. However, the correlation between precipitation increase and the regional vegetation restoration is still controversial. To explore the main factors influencing the regional precipitation change, this study selected five potential influencing factors including potential evapotranspiration (PET), normalized difference vegetation index (NDVI), precipitable water (PW), surface temperature (ST), and water vapor transport (WVT). We used the statistical methods to analyze the spatial-temporal distribution of precipitation before and after the GFGP and to quantify the relative influence degree of different factors to precipitation change. The results show that: (1) The precipitation increased significantly (95\% confidence level) after the GFGP, with an increase rate of $4.96 \mathrm{~mm} \mathrm{a}^{-1}$; (2) from the perspective of spatial-temporal distribution, the precipitation in the southern part of the Loess plateau was significantly increasing with an increase rate of $20-50 \mathrm{~mm}$ in the period of 2000-2014; (3) the relative influence degree of NDVI to precipitation increased after the GFGP, and the annual precipitation $\left(\mathrm{PRE}_{\mathrm{A}}\right)$ and summer precipitation $\left(\mathrm{PRE}_{\mathrm{S}}\right)$ was more influenced by NDVI (relative influence degree of $30.18 \%$ and $31.37 \%$, respectively) compared with winter precipitation. In winter, the PW and the PET are the main influencing factors for the precipitation change with relative influence degrees of $30.13 \%$ and $27.64 \%$, respectively. Based on this study, we speculate that the warming and wetting trend of the Loess Plateau in recent years is not only closely related to global climate change, but also significantly affected by local climate change brought by vegetation restoration. The above conclusions are important for future ecological restoration and water resources management in the water-scarce Loess Plateau.
\end{abstract}

Keywords: grain for green project; precipitation; vegetation restoration; contribution rate; the Loess Plateau

\section{Introduction}

The Loess Plateau is located in a semi-arid and semi-humid region. The main land use types are farmland and grassland [1]. At the same time, this area is the largest loesscovered area in the world. With the impact of climate change (extreme precipitation and drought) and human activities (overgrazing and deforestation) [2,3], a series of ecological and environmental problems, such as soil erosion, drought, and water scarcity, and siltation of rivers and lakes on the Loess Plateau have been aggravated [3]. Therefore, the Chinese government implemented the "Grain for Green Project" (GFGP) in the 1990s in the Loess Plateau. The implementation of the GFGP has led to dramatic changes in land use/land cover, with the vegetation cover increasing by 25\% from 1999 to 2013 [4], and the change 
rate of normalized difference vegetation index (NDVI) in the new century is 10 times higher than that before 1999 [1]. With the evapotranspiration increase and soil drying induced by vegetation recovery, observed stream flow has also declined by approximately $50 \%$ from the 1950s to 2015 [5]. The improved vegetation cover, in combination with engineering measures (e.g., check dam, terrace, level furrow, and fish-scale pits), has improved soil properties, reduced soil erosion, and saved incoming water to prevent sediment load from entering the river [6]. As a result, sediment discharge into the Yellow River has declined by approximately $90 \%$ over the past 60 years [5]. In general, the vegetation restoration effectively reduced the surface runoff and river sediment load [7], but it also brought out some problems of water resources.

Direct local-scale observations suggest a considerable reduction in surface water yield over the region after revegetation, including soil desiccation, stunted or "small old" trees, and even plant mortalities. Extra planted vegetation consumes water, and when evapotranspiration exceeds precipitation, a soil water imbalance occurs, which plays a crucial role in the formation of dried soil layers. The dried soil layer is, in turn, deemed a serious obstacle to sustainable vegetation restoration, suggesting a negative feedback of revegetation on local water yield and subsequently on vegetation growth. For a long time, scholars believed that the Loess Plateau tends to be warm and dry, but in recent years, especially since the 1990s, there has been a significant warming and wetting trend in this region [2,8-11]. The debate on the ecological sustainability of the uneven distribution of water resources on the Loess Plateau continues, but the sustainability of afforestation in the Loess Plateau region needs to be judged according to the local hydrology and meteorology. The knowledge of the relationship between local precipitation and afforestation characteristics would indeed be highly valuable for a more comprehensive evaluation of the impacts of revegetation on surface water yield, thus guiding the ecological restoration implementation.

Precipitation plays a critical role in the human life and hydrological cycle [12,13]. The change in precipitation leads to an aggravation of natural hazards such as floods, drought, and soil erosion [14]. At present, there are many studies on the influence of atmospheric circulation [15], meteorological factors [16], and aerosol factors $[17,18]$ on precipitation. However, there are few studies paying attention to the impact of vegetation restoration and the local microclimate on precipitation. Gao et al. [2] analyzed the changes in actual evapotranspiration (AET), normalized difference vegetation index (NDVI), and precipitation in the Loess Plateau during 1990-2014, and they found that the precipitation increase may cause an increase in AET, and in turn, the AET increase may also influence the precipitation. Li et al. [9] analyzed the impacts of the Chinese Grain for Green program and climate change on vegetation in the Loess Plateau during 1982-2015, and found that precipitation has mainly contributed to the increase in NDVI in the southeastern region; meanwhile, they found that with the increase in vegetation coverage, the change in underlying surface also had a feedback effect on regional precipitation. Therefore, to further analyze the precipitation change and to identify its potential driving factors in the Loess Plateau, it is urgent to comprehensively consider both climate factors and vegetation restoration factors, and quantitatively analyze the main contribution factors of precipitation under the condition of global climate change and fast land use/cover change. At present, the analysis methods of precipitation driving factors mainly include regression analysis [19], machine learning [15], and principal component analysis [20]. Regression analysis cannot solve the problem of multicollinearity among predictors. Principal component analysis is mainly used to extract important information to explain data structure [21], while principal component regression analysis can be used for driver factor analysis and is also widely used in predictive analysis. Chen et al. [21] analyzed the spatial variation in driving factors of irrigation water consumption based on principal component regression, and pointed out that the water consumption structure, irrigation technique, and planting structure were major influential factors in most provinces of China. Tang et al. [22] integrated principal component analysis with statistically based models for analysis of causal factors 
and landslide susceptibility mapping; the results showed that rainfall and land use were essential in predicting both loess landslide and rockfall occurrences. Zeng [23] analyzed the influence of NDVI, EVI, precipitation, and temperature on surface water fluctuation based on regression analysis, and pointed out that vegetation cover is an important factor in controlling permanent water changes. Therefore, we can use principal component regression analysis to eliminate multicollinearity in independent variables, and the weights coefficient can be used to measure the influence of the factors to precipitation.

In the past decades, jointly influenced by climate change and ecological restoration, the spatial and temporal pattern of precipitation in the Loess Plateau was undergoing a significant change. However, the potential influencing factors and their influence on local precipitation are still unclear and not well revealed. Therefore, this study aims to analyze the main influencing factors of precipitation in the condition of vegetation recovery and climate change. Based on previous studies and the local conditions of the Loess Plateau, we selected five potential influencing factors, including potential evapotranspiration (PET), normalized difference vegetation index (NDVI), precipitable water (PW), surface temperature (ST), and water vapor transport (WVT). The paper is structured as follows: (1) To collect the precipitation data and analyze the spatial and temporal characteristics of precipitation before and after the GFGP in the Loess Plateau; (2) to analyze the factors and reveal the spatial and temporal characteristics of each factor; (3) to use the statistical methods to quantitatively analyze the main influencing factors of precipitation before and after the GFGP, and discuss the impact of vegetation restoration on precipitation. The above findings in this research may provide the basic reference for the precipitation prediction in the future. Meanwhile, it may be a great significance for the ecological restoration and water resource management of the Loess Plateau.

\section{Study Area and Data Collection}

\subsection{Study Area}

The Loess Plateau is situated in the upper and middle reaches of the Yellow River (as shown in Figure 1), with a latitude between $33^{\circ} 43^{\prime}$ and $41^{\circ} 16^{\prime} \mathrm{N}$ and longitude between $100^{\circ} 54^{\prime}$ and $114^{\circ} 33^{\prime} \mathrm{E}$. The plateau is covered with a deep layer of loess with an average thickness of 50-200 m [24]. The overall terrain is high in the northwest and low in the southeast, ranging from 94 to $5000 \mathrm{~m}$ and with an area of $648,700 \mathrm{~km}^{2}$, approximately.

The Loess Plateau belongs to two temperate zones (warm temperate zone in the south and middle temperate zone in the north). It has the typical continental monsoon climate characteristics. The annual average temperature is from $4.3{ }^{\circ} \mathrm{C}$ to $14.3^{\circ} \mathrm{C}$, and the annual precipitation decreases gradually from the southeast to northwest, ranging from 200 to $750 \mathrm{~mm}$. The total precipitation in the rainy season (June-September) accounts for about $65 \%$ of the annual precipitation [25].

\subsection{Data}

This study mainly used the following data:

(1) Meteorological data. Meteorological data were collected from the China Meteorological Data Network (http:/ / data.cma.cn/), and the temporal resolution of the data is 1 day. Meteorological data mainly include temperature, air pressure, wind speed, relative humidity, sunshine duration, and ground temperature data of 52 meteorological stations in the Loess Plateau, as shown in Table 1 and Figure 1. The precipitation data were collected from 368 rainfall gauge stations in and around the Loess Plateau region, and the spatial distribution is shown in Figure 1. The temporal resolution of the data is 1 day. 


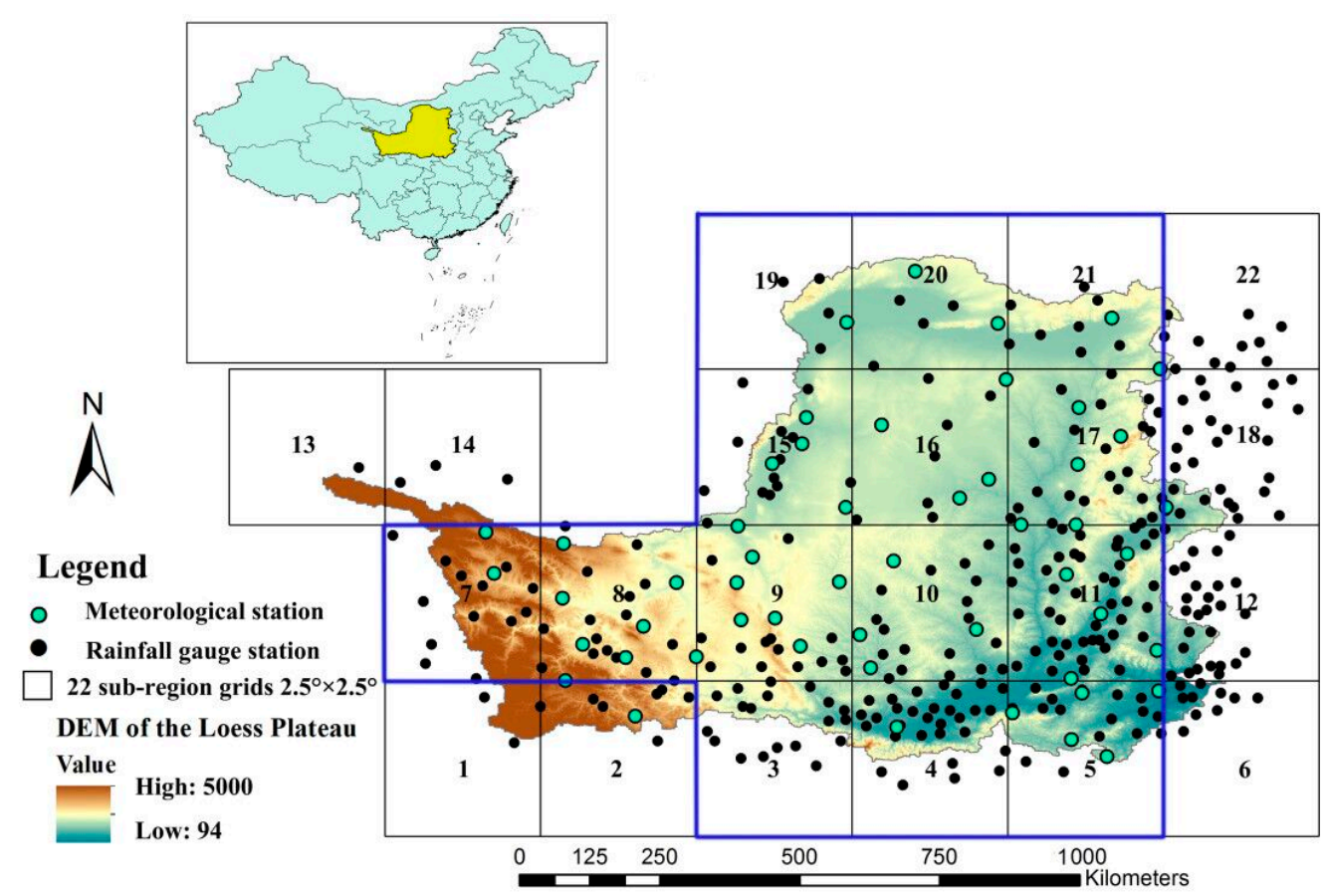

Figure 1. Geographical location of the Loess Plateau and distribution of meteorological stations and 22 sub-regions.

Table 1. The names and coordinates of 52 meteorological stations.

\begin{tabular}{|c|c|c|c|c|c|c|c|}
\hline Station & Name & Lon & Lat & Station & Name & Lon & Lat \\
\hline 52,765 & Menyuan & 101.62 & 37.38 & 53,740 & Hengshan & 109.23 & 37.93 \\
\hline 52,787 & Wushaoling & 102.87 & 37.20 & 53,754 & Suide & 110.22 & 37.50 \\
\hline 52,866 & Xining & 101.77 & 36.62 & 53,764 & Lishi & 111.10 & 37.50 \\
\hline 52,876 & Minhe & 102.85 & 36.32 & 53,772 & Taiyuan & 112.55 & 37.78 \\
\hline 52,895 & Jingyuan & 104.68 & 36.57 & 53,806 & Haiyuan & 105.65 & 36.57 \\
\hline 52,983 & Yuzhong & 104.15 & 35.87 & 53,810 & Tongxin & 105.90 & 36.98 \\
\hline 52,984 & Linxia & 103.18 & 35.58 & 53,817 & Guyuan & 106.27 & 36.00 \\
\hline 52,986 & Lintao & 103.87 & 35.37 & 53,821 & Huanxian & 107.30 & 36.58 \\
\hline 52,996 & Huajialing & 105.00 & 35.38 & 53,853 & Xixian & 110.95 & 36.70 \\
\hline 53,336 & Wulatehouqi & 108.52 & 41.57 & 53,863 & Jiexiu & 111.92 & 37.03 \\
\hline 53,446 & Baotou & 109.85 & 40.67 & 53,868 & Linfen & 111.50 & 36.07 \\
\hline 53,463 & Huhehaote & 111.68 & 40.82 & 53,903 & Xiji & 105.72 & 35.97 \\
\hline 53,478 & Youyu & 112.45 & 40.00 & 53,915 & Pingliang & 106.67 & 35.55 \\
\hline 53,513 & Linhe & 107.42 & 40.75 & 53,923 & Xifengzhen & 107.63 & 35.73 \\
\hline 53,519 & Huinong & 106.77 & 39.22 & 53,929 & Changwu & 107.80 & 35.20 \\
\hline 53,529 & Etuokeqi & 107.98 & 39.10 & 53,942 & Luochuan & 109.50 & 35.82 \\
\hline 53,543 & Hedong & 109.98 & 39.83 & 53,959 & Yuncheng & 111.02 & 35.03 \\
\hline 53,564 & Hequ & 111.15 & 39.38 & 53,975 & Yangcheng & 112.40 & 35.48 \\
\hline 53,614 & Yinchuan & 106.22 & 38.48 & 56,080 & Hezuo & 102.90 & 35.00 \\
\hline 53,615 & Taole & 106.70 & 38.80 & 56,093 & Minxian & 104.02 & 34.43 \\
\hline 53,646 & Yulin & 109.70 & 38.23 & 57,034 & Wugong & 108.22 & 34.25 \\
\hline 53,663 & Wuzhai & 111.82 & 38.92 & 57,046 & Huashan & 110.08 & 34.48 \\
\hline 53,664 & Xingxian & 111.13 & 38.47 & 57,051 & Sanmenxia & 111.20 & 34.80 \\
\hline 53,705 & Zhongning & 105.67 & 37.48 & 57,067 & Lushi & 111.03 & 34.05 \\
\hline 53,723 & Yanchi & 107.40 & 37.78 & 57,071 & Mengjin & 112.43 & 34.83 \\
\hline 53,738 & Wuqi & 108.18 & 36.83 & 57,077 & Luanchuan & 111.60 & 33.78 \\
\hline
\end{tabular}

(2) Reanalysis Dataset. NCEP/NCAR reanalysis dataset was created through the cooperative efforts of the National Centers for Environmental Prediction (NCEP) and National Center for Atmospheric Research (NCAR), available at (https:/ / psl.noaa.gov / data/ gridded/data.ncep.reanalysis.html). The spatial resolution of the dataset is $2.5^{\circ} \times 2.5^{\circ}$, 
and the temporal resolution is 1 day. The dataset used in this study included $\mathrm{u} / \mathrm{v}$ wind, and specific humidity for 1000, 925, 850, 700, 600, 500, 400, and $300 \mathrm{hPa}$; precipitation water (PW).

(3) Remote sensing data. Before 1999, the NDVI data were from the National Earth System Science Data Center, National Science \& Technology Infrastructure of China (http:/ / www.geodata.cn). After 1999, the NDVI data were from MODIS datasets (https: //ladsweb.modaps.eosdis.nasa.gov/search/).

\section{Methodologies}

\subsection{Technical Framework}

This paper aims to study the change in precipitation before and after the implementation of the Grain for Green Project (GFGP) in the Loess Plateau and to analyze the main influencing forces behind this. First, the Mann-Kendall (M-K) test and Hurst analysis method are used to study the trend and persistence of precipitation before and after the GFGP in the Loess Plateau at the spatial-temporal scale. Then, five main factors were selected, including PET, NDVI, PW, ST, and WVT, and their changes were analyzed at spatial-temporal scales. Finally, the statistical method was implemented to quantitatively evaluate the main influencing factors of precipitation before and after the GFGP. The research framework of this article is as shown in Figure 2.

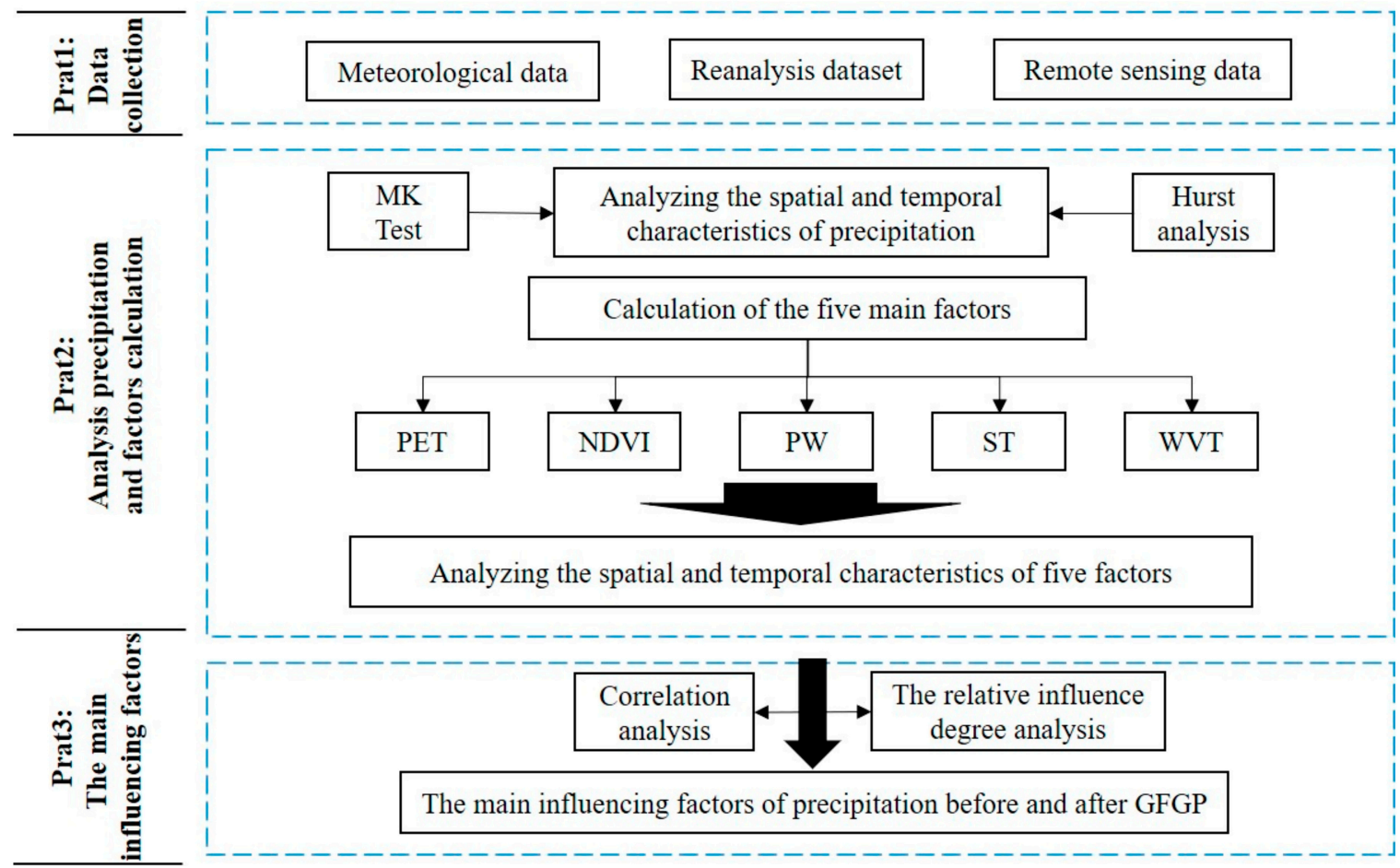

Figure 2. Technical roadmap of this study.

\subsection{Trend Analysis}

The Mann-Kendall (M-K) test and Hurst analysis method were introduced to analysis the changing trends of precipitation and the other five factors on the Loess Plateau. Based on the M-K test, the trends of the five factors and precipitation before and after the GFGP are analyzed, and the Hurst analysis method is used to analyze the continuity of precipitation after the GFGP. 


\subsubsection{Mann-Kendall Trend Test with Trend-Free Pre-Whitening}

Mann-Kendall is a nonparametric analysis used to estimate the significance of the trend of hydrological and meteorological [26]. The evaluating variable $Z$ is often used to estimate whether a series has a significant trend or not, which was calculated as follows:

$$
\begin{gathered}
Z=\left\{\begin{array}{l}
\frac{S-1}{\sqrt{\operatorname{Var}(S)}} \text { when } S>0 \\
0 \text { when } S=0 \\
\frac{S+1}{\sqrt{\operatorname{Var}(S)}} \text { when } S<0
\end{array}\right. \\
S=\sum_{i=1}^{n-1} \sum_{j=i+1}^{n} \operatorname{sign}\left(X_{j}-X_{i}\right) \\
\operatorname{sign}\left(X_{j}-X_{i}\right)=\left\{\begin{array}{c}
+1 \text { when }\left(X_{j}-X_{i}\right)>0 \\
0 \text { when }\left(X_{j}-X_{i}\right)=0 \\
-1 \text { when }\left(X_{j}-X_{i}\right)<0
\end{array}\right.
\end{gathered}
$$

where $X_{i}$ and $X_{j}$ are the sequential values, and $n$ is the length of the time series.

The variance of $S$ is given by the following equation:

$$
\operatorname{Var}(S)=\frac{n(n-1)(2 n+5)}{18}
$$

where $n$ is the length of the data series.

The evaluating variable $Z$ indicates the trend of the time series; when $Z>0$, the trend is increasing; otherwise, it is decreasing. When $|Z| \geq 1.64$, the trend is significant at $90 \%$ confidence; when $|Z| \geq 1.96$, the trend is significant at $95 \%$ confidence [27].

\subsubsection{Hurst Exponent and Rescaled Range $(R / S)$ Analysis}

The Hurst analysis is a useful method to understand the properties of a time series [28,29] and is widely used in hydrology, climatology, and ecology. Rescaled range $(R / S)$ analysis is the method widely used to calculate the $\mathrm{H}$ exponent. The basic principles of the R/S analysis method are as follows:

Suppose there is a time series $\xi(t)=\{\xi \mid t=0,1,2, \cdot \cdot, N\}$, and the time series is cut into $\mathrm{m}(\mathrm{m}=\mathrm{N} / n)$ continuous subsequences with a length of $n(n<\mathrm{N})$; then, each time subsequence can be presented as:

$$
\xi_{n}=\sum_{i=1}^{n} \xi_{i}
$$

The average value of a subsequence can be presented as:

$$
\overline{\xi_{n}}=\frac{1}{n} \xi_{n}
$$

Then, the ith cumulated dispersion is:

$$
X(i, n)=\sum_{t=1}^{i}\left(\xi_{i}-\overline{i \xi_{n}}\right)
$$

The range is:

$$
R(n)=\max _{0 \leq i \leq n} X(i, n)-\min _{0 \leq i \leq n} X(i, n)
$$

where $1 \leq i \leq n$. 
The standard deviation is:

$$
S(n)=\left[\frac{1}{n} \sum_{i=1}^{n}\left(\xi_{i}-\overline{\xi_{n}}\right)^{2}\right]^{1 / 2}
$$

When the characteristics of the time series $\xi(t)=\{\xi \cdot \mid t=0,1,2, \cdot ., N\}$ is a constant scale, the rescaled range of $R / S$ for any length $\mathrm{n}$ can be presented as:

$$
\frac{R(n)}{S(n)}=(\alpha n)^{H}
$$

where $\alpha$ is a constant, and $H$ is the Hurst exponent and estimated by fitting the above formula. When $H=0.5$, the time series is random, indicating that the future trend is independent of the past. When $0.5<H<1$, the future change trend is consistent with the past. The closer the value is to 1 , the stronger the continuity; when $0<H<0.5$, the future change trend is opposite to the past. The closer the value is to 0 , the stronger the anti-continuity.

\subsection{Calculation of the Five Main Factors}

In this study, we aim to analyze the main driving factors of precipitation in the condition of vegetation recovery and climate change, and comprehensively considered five factors. PET is selected as the climate factor, NDVI and ST as the underlying surface change factor, and PW and WVT as the water vapor factor of atmospheric circulation. Moreover, $\mathrm{CO}_{2}$ is also a potential influencing factor worthy of consideration. However, the previous study showed that the elevated $\mathrm{CO}_{2}$ was not the most primary factor for ET change in the Three-North Region including the Loess Plateau in China [30]. Meanwhile, there are no gridded data of $\mathrm{CO}_{2}$ concentration from 1985 to 2014 in the world. Therefore, we decided not to consider the effect of $\mathrm{CO}_{2}$ in this study. Finally, the five main factors are calculated as follows.

\subsubsection{Potential Evapotranspiration (PET)}

Potential evapotranspiration (PET) is a typical indicator that reflects the comprehensive effect of the climate [31]. Therefore, we selected PET as the climate factor. PET is estimated through the Penman-Monteith (P-M) method that is based on the meteorological data and parameters, which is widely used and recommended by numerous international organizations. The formula is as follows:

$$
\mathrm{PET}=\frac{0.408 \Delta\left(R_{n}-G\right)+\gamma \cdot \frac{900}{273+T} \cdot u_{2} \cdot\left(e_{a}-e_{d}\right)}{\Delta+\gamma\left(1+0.34 \cdot u_{2}\right)}
$$

where PET is the potential evapotranspiration, in $\mathrm{mm} /$ day; $R_{n}$ is the net solar radiation, in $\mathrm{MJ} / \mathrm{m}^{2} ; \mathrm{G}$ is the soil heat flux, in $\mathrm{MJ} / \mathrm{m}^{2} ; \Delta$ is the slope of the saturation vapor pressure curve, in $\mathrm{kPa} /{ }^{\circ} \mathrm{C}$; $\gamma$ is the psychometric constant, in $\mathrm{kPa} /{ }^{\circ} \mathrm{C} ; \mathrm{T}$ is the daily temperature, in ${ }^{\circ} \mathrm{C} ; e_{a}$ is the saturation vapor pressure, in $\mathrm{kPa} ; e_{d}$ is the actual water vapor pressure, in $\mathrm{kPa} ; u_{2}$ is the daily average wind speed at $2 \mathrm{~m}$ height, in $\mathrm{m} / \mathrm{s}$. The data of temperature, air pressure, wind speed, relative humidity, and sunshine duration were collected from the 52 meteorological stations on the Loess Plateau. $R_{n}$ refers to the surface ingoing energy minus the surface outgoing energy, which can be expressed as:

$$
R_{n}=(1-\alpha) K_{\text {in }}+\left(L_{\text {in }}-L_{\text {out }}\right)-\left(1-e_{0}\right) L_{\text {in }}
$$

where $K_{\text {in }}$ is the incoming short-wave radiation $\left(\mathrm{W} / \mathrm{m}^{2}\right) ; L_{\text {in }}$ and $L_{\text {out }}$ are the incoming long-wave radiation and outcoming long-wave radiation $\left(\mathrm{W} / \mathrm{m}^{2}\right)$, respectively; $\alpha$ is the surface short-wave albedo; and $e_{0}$ is the land surface emissivity. 


\subsubsection{Normalized Difference Vegetation Index (NDVI)}

Vegetation coverage in the Loess Plateau has increased significantly after the GFGP. The impact of vegetation changes on precipitation should be considered in this study. Therefore, we selected Normalized Difference Vegetation Index (NDVI) as one of the five factors. NDVI data before 1999 were collected from the National Earth System Science Data Center, National Science \& Technology Infrastructure of China (http:/ / www.geodata.cn), which has a spatial resolution of $0.05^{\circ}$ and a temporal resolution of 8 days; NDVI data after 1999 were collected from the MODIS datasets (https: / ladsweb.modaps.eosdis.nasa.gov/ search/), with a spatial resolution of $250 \mathrm{~m}$ and a temporal resolution of 16 days.

In order to keep the spatial consistency of the NDVI, we used the maximum value composite method [32] to synthesize the 8 days and 16 days NDVIs into monthly NDVIs, and resampled them to $0.05^{\circ} \times 0.05^{\circ}$ resolution based on WGS-1984. Annual NDVI was defined as the average monthly composite NDVI of 12 months, summer NDVI was defined as the average monthly composite NDVI from April to September, and winter NDVI was defined as the average monthly composite NDVI from October to March.

\subsubsection{Precipitable Water (PW)}

Precipitable water (PW) plays a decisive role in latent heat transportation, cloud formation, and the occurrence of precipitation [33-35], which is defined as the depth of liquid water produced after all the water vapor in the unit air column has condensed and landed. In this study, we selected PW as one of the main factors. Zhao et al. [36] found that NCEP reanalysis data were highly correlated with the observational data from the perspective of climatological statistics. Therefore, the data of PW were collected from the $\mathrm{NCEP} / \mathrm{NCAR}$ reanalysis dataset with a spatial resolution of $2.5^{\circ} \times 2.5^{\circ}$ and a temporal resolution of one day.

\subsubsection{Surface Temperature (ST)}

Temperature is the main factor that affects precipitation [37,38]. After the GFGP, the vegetation coverage of the Loess Plateau changed greatly, and vegetation variation can affect the surface temperature (ST) by altering surface albedo and evapotranspiration [39]. Therefore, we chose ST as the temperature factor of the underlying surface change. The surface temperature comes from the China Meteorological Data Network (http:/ / data.cma. $\mathrm{cn} /$ ), including surface temperature data at 52 sites in the Loess Plateau, with a temporal resolution of one day.

\subsubsection{Water Vapor Transport}

Precipitation originates from local evaporation moisture and external water vapor transport (WVT) [40]. Water vapor transport (WVT) represents the amount of water vapor transfer through a unit area in a unit interval. In this study, we selected WVT as the external water vapor factor. WVT is calculated as follows [41,42]:

$$
\begin{aligned}
& Q_{x}=-\frac{1}{g} \int_{p_{s}}^{p} u q d p \\
& Q_{y}=-\frac{1}{g} \int_{p_{s}}^{p} v q d p
\end{aligned}
$$

where $Q_{x}$ and $Q_{y}$ indicate the zonal and meridional water vapor transportation, respectively, $g$ is the gravitational acceleration, $p_{s}$ is the surface pressure, $p$ is the pressure at $300 \mathrm{hPa}, q$ is the specific humidity, and $\mathrm{u} / \mathrm{v}$ is the zonal and meridional wind.

According to the spatial resolution of the NCEP/NCAR reanalysis dataset, this study divided the study area into 22 grids of $2.5^{\circ} \times 2.5^{\circ}$, as shown in Figure 1 . The east boundary of grids $21,17,11$, and 5 is defined as the east boundary. The south boundary of grids 7,8 , 3,4 , and 5 is the south boundary of the region. The west boundary of grids $19,15,7$, and 3 is the west boundary. The north boundary of grids $7,8,19,20$, and 21 is the north boundary. 
The water vapor transport of the east, south, west, and north boundary is the sum of water vapor transport volume at the corresponding grid boundary. The zonal water vapor net input is equal to the results of water vapor flux of the western boundary subtracted by those of the eastern boundary, and the meridional component is equal to the southern boundary minus the northern boundary $[41,43]$. Then, the net water vapor input (WVT) of the Loess Plateau is calculated.

\subsection{Principal Component Regression Analysis}

In order to eliminate the multi-collinearity among various factors, principal component regression analysis was used to quantitatively analyze the impact of each factor on precipitation. Principal component analysis can transform multiple indicators into fewer well-represented comprehensive indicators that reduce dimensionality and simplify the data structure [44-46].

Suppose that there are $p$ indicators involved with a certain object, denoted by $X_{1}, X_{2}, \ldots, X_{p}$. These $p$ indicators compose a $p$-dimensional vector: $X=\left(X_{1}, X_{2}, \ldots, X_{p}\right)$. After dimension reduction, new variables $F_{1}, F_{2}, \ldots, F_{m}(\mathrm{~m} \leq p)$ are obtained:

$$
\left\{\begin{array}{c}
F_{1}=l_{11} x_{1}+l_{12} x_{2}+\ldots+l_{1 p} x_{p} \\
F_{2}=l_{21} x_{1}+l_{22} x_{2}+\ldots+l_{2 p} x_{p} \\
\ldots \ldots \\
F_{m}=l_{m 1} x_{1}+l_{m 2} x_{2}+\ldots+l_{m p} x_{p}
\end{array}\right.
$$

In this study, the principal component analysis method is used to convert five factors into several independent principal components. Then, combined with multiple linear regression, the principal component with a contribution rate more than $90 \%$ is selected for regression analysis [21,22], and the relative influence degree of each factor is calculated by the weight of the regression coefficient, which is calculated as follows:

$$
\begin{aligned}
\mathrm{Y} & =a_{1} X_{1}+a_{2} X_{2}+\ldots+a_{\mathrm{P}} X_{\mathrm{P}} \\
\eta_{i} & =\frac{\left|a_{i}\right|}{\left|a_{1}\right|+\left|a_{2}\right|+\left|a_{3}\right|+\ldots\left|a_{p}\right|}
\end{aligned}
$$

where $\mathrm{Y}$ is the dependent variable, $X_{\mathrm{i}}$ and $a_{\mathrm{i}}$ are the independent variables and the corresponding regression coefficients, and $\eta_{i}$ is the relative influence degree of the change in $X_{i}$ to the change in $\mathrm{Y}$. We eliminated the influence of dimensionality through data standardization [47], and the statistical calculations in this study were through SPSS 20.

\section{Results}

\subsection{The Spatial-Temporal Characteristic of Precipitation Changes in the Loess Plateau}

\subsubsection{The Temporal Variability of Precipitation}

In this study, we defined the period before the GFGP as base Period I (1985-1999), and the period after the GFGP as change Period II (2000-2014). The precipitation in the Loess Plateau is concentrated in summer and autumn, and the seasonal precipitation fluctuates greatly. Therefore, we defined the summer scale as April to September and the winter scale as October to March. Then, the temporal variability of precipitation is shown in Figure 3.

As shown in Figure 3, during Period I, the annual precipitation ( $\left.P R E_{A}\right)$, summer precipitation $\left(P R E_{S}\right)$, and winter precipitation $\left(P R E_{W}\right)$ all showed a decreasing trend. The $\mathrm{PRE}_{\mathrm{A}}$ decreased at a rate of $2.22 \mathrm{~mm} \mathrm{a}{ }^{-1}$, which is most significant. The PRE and PRE decreased at a rate of 1.56 and $1.19 \mathrm{~mm} \mathrm{a}^{-1}$, respectively. However, based on the $\mathrm{M}-\mathrm{K}$ trend test, the PRE $\mathrm{A}, \mathrm{PRE}_{\mathrm{S}}$, and $\mathrm{PRE}_{\mathrm{W}}$ decreasing trend is not statistically significant. In Period II, the $P R E_{A}$ and $P R E_{S}$ showed a significant increasing trend. The $P R E_{A}$ increased at a rate of $4.96 \mathrm{~mm} \mathrm{a}^{-1}$ and the PRE $\mathrm{S}$ increased at a rate of $5.63 \mathrm{~mm} \mathrm{a}^{-1}$. Moreover, based on the M-K test, the $Z$ values of both $P_{R E}$ and $P R E_{S}$ were 2.43 with a $95 \%$ confidence level. The PRE showed a slight decreasing trend at a rate of $0.47 \mathrm{~mm} \mathrm{a}^{-1}$. In general, precipitation in the 
Loess Plateau was mainly affected by the $\mathrm{PRE}_{\mathrm{S}}$, and which had increased significantly after the GFGP.

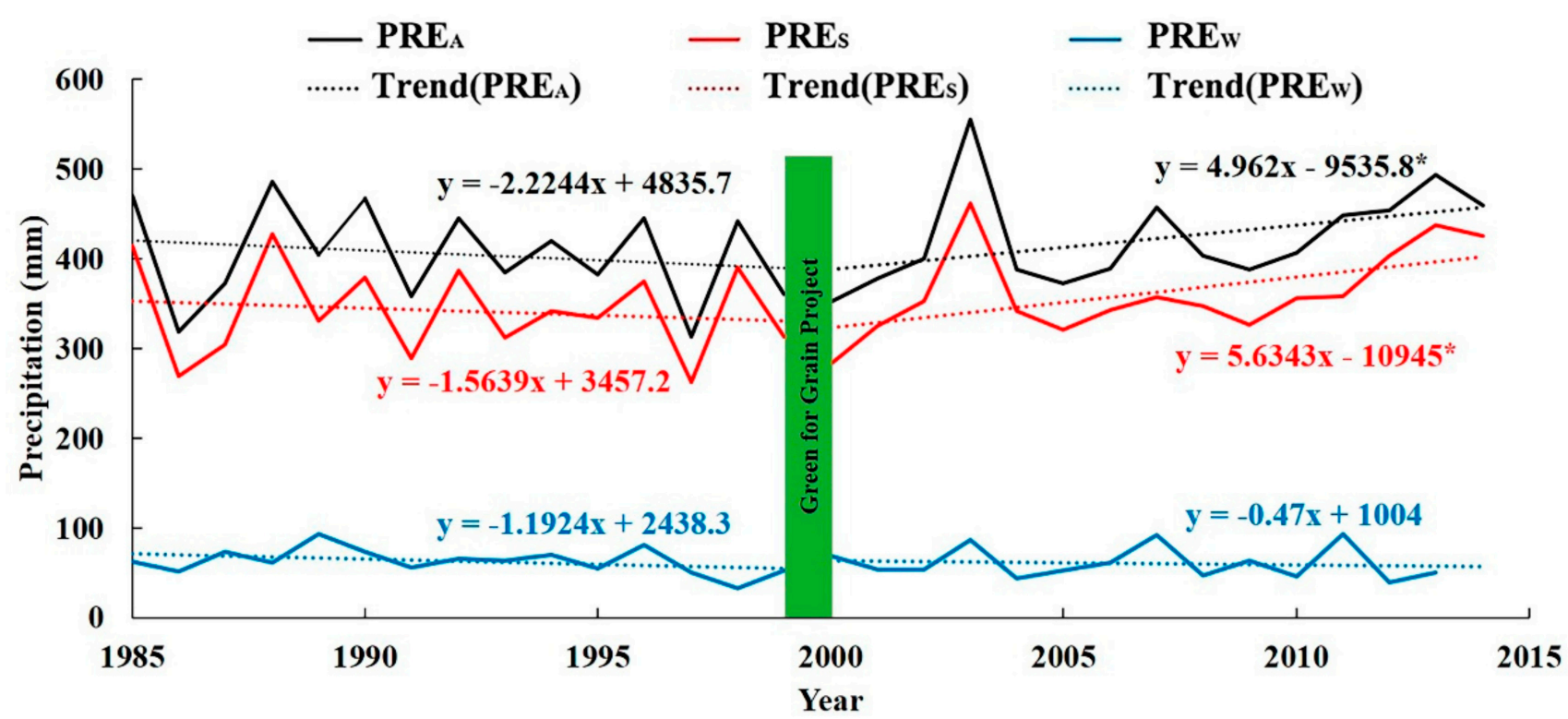

Figure 3. The annual and seasonal changes of precipitation (“*” indicates that the trend is statistically significant at the $95 \%$ confidence level).

4.1.2. Changes and the Continuity of Station-Scale Precipitation in the Loess Plateau before and after GFGP

Precipitation in the Loess Plateau has increased significantly since 1999. In order to further analyze the trend and its significance of precipitation at each site scale before and after the GFGP, this study adopted the M-K test to calculate the precipitation trends at 368 meteorological stations in Period I and Period II. Furthermore, the continuity of the trend of precipitation after the GFGP was tested based on the Hurst analysis method.

As shown in Figure $4 a, b$, based on the $Z$ value from the M-K test, there were 267 stations showing decreasing trends $(Z<0)$ in Period I, accounting for $72.6 \%$ of all stations. Except for a few stations in the northeast area, almost all the stations showed decreasing trends, in which 17 stations were with a $90 \%$ confidence level. In Period II, there were 311 stations showing an increasing trend $(Z>0)$, accounting for $84.5 \%$ of all stations, in which 37 stations were with a $90 \%$ confidence level. The central and northern parts of stations showed a significant increasing trend. At the same time, based on Hurst analysis, the $\mathrm{H}$ value of precipitation in the central, northern, and southwestern Loess Plateau after 1999 was all greater than 0.55 (Figure 4c), which means that the precipitation had a strong continuity under the current conditions. Generally, precipitation in the Loess Plateau was dramatically different before and after the GFGP. After 1999, precipitation in the central and the northeastern region had increased significantly.

\subsubsection{The Spatial Variability of Precipitation}

The spatial distribution and variation in precipitation on the Loess Plateau in Period I and Period II, and the difference in precipitation between the two periods are shown in Figure 5. 


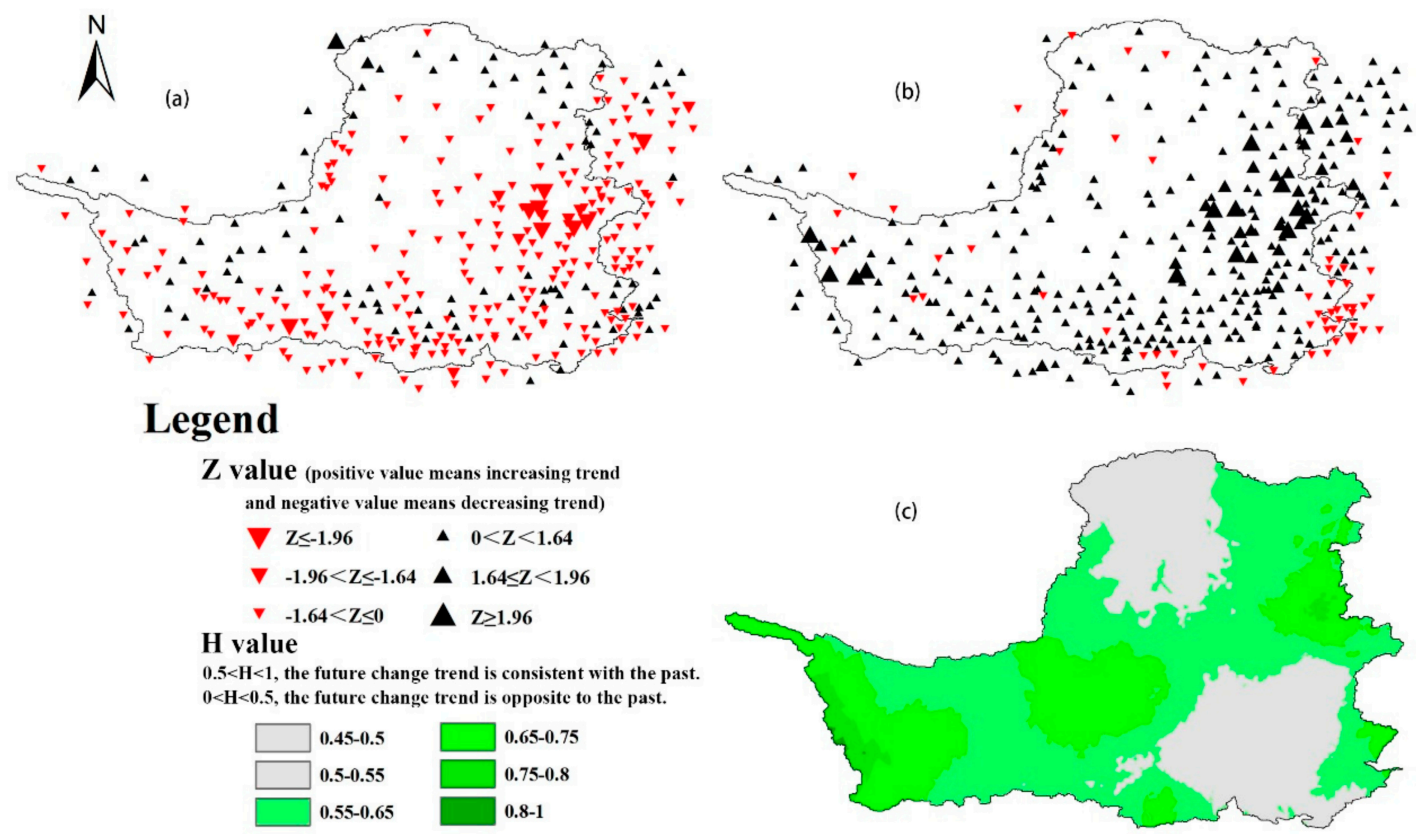

Figure 4. The $\mathrm{Z}$ value based on the Mann-Kendall (M-K) test used to study the trend of precipitation in Period I (a) and Period II (b), and the H value based on Hurst analysis used to study the continuity of precipitation after the Grain for Green Project (GFGP) (c).

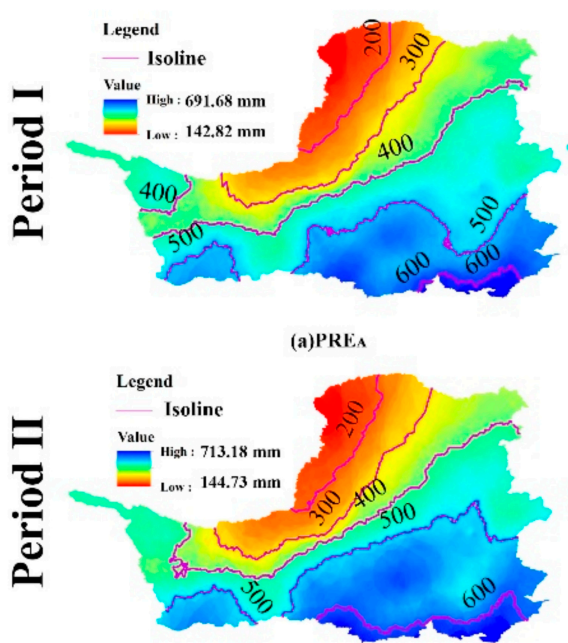

(d) PREA

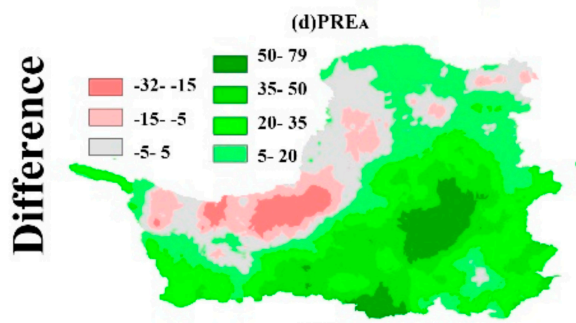

(g)PREA

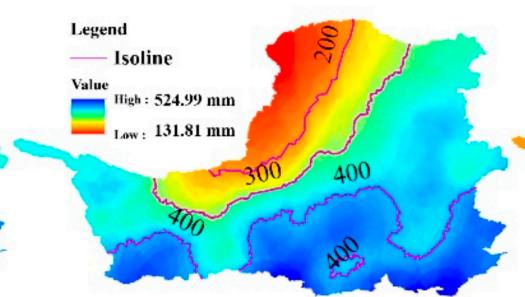

(b) PRES

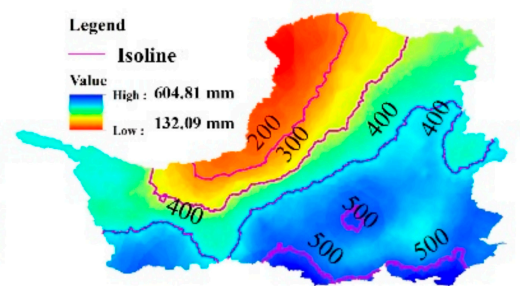

(e)PREs

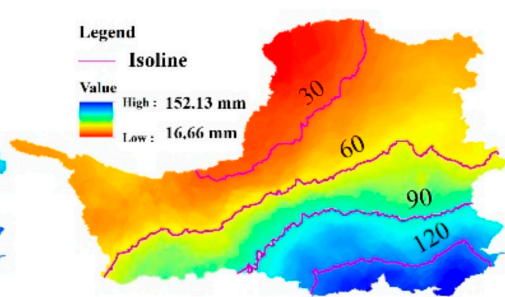

(c)PREw

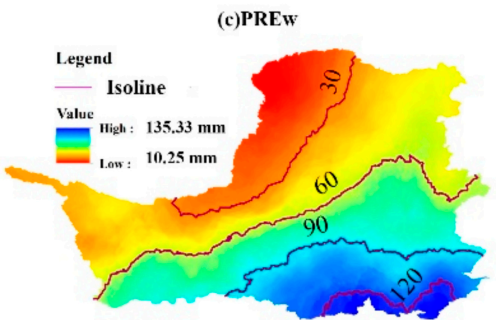

(f)PREw

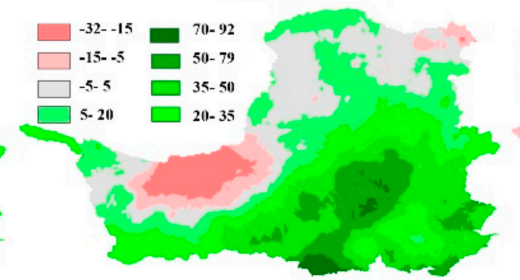

(h)PREs

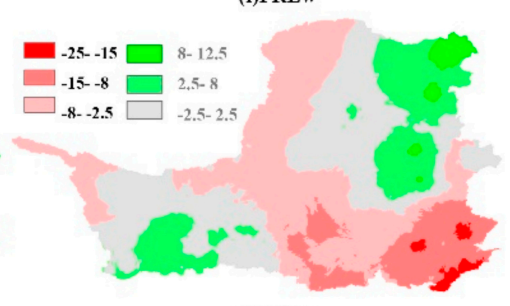

(i)PREw

Figure 5. The spatial distribution of precipitation in Period I ((a) annual precipitation $\mathrm{PRE}_{\mathrm{A}}$, (b) summer precipitation PRES, (c) winter precipitation PRE $\left.E_{W}\right)$ and Period II $(\mathbf{d}, \mathbf{e}, \mathbf{f})$ and the difference in precipitation between the two periods $(\mathbf{g}, \mathbf{h}, \mathbf{i})$.

The precipitation on the Loess Plateau decreased from the southeast to northwest, and the spatial distribution and the difference distribution of the PRES were highly consistent with the PRE $\mathrm{P}_{\mathrm{A}}$. In Period II, the PRE $\mathrm{A}$ was $144.73-713.18 \mathrm{~mm}$, decreasing from the southeast to northwest, and the PRES decreased from the southeast to northwest with $132.09-604.81 \mathrm{~mm}$. 
From the difference in the precipitation in Figure $5 g-i$, the $P_{R E}$ and the PREs in the southeast increased significantly, with the rates mainly between 20 and $50 \mathrm{~mm}$, and mostly all the regions showing increasing trends. The variation in the $P R E_{W}$ was mainly between -8 and $2.5 \mathrm{~mm}$. To sum up, after implementing the GFGP, the $\mathrm{PRE}_{\mathrm{A}}$ and $\mathrm{PRE}_{\mathrm{S}}$ in the southeast and central regions increased, while the spatial variation in the $\mathrm{PRE}_{\mathrm{W}}$ changed little.

\subsection{The Spatial-Temporal Characteristic of the Main Influencing Factors}

\subsubsection{The Annual and Seasonal Variation in the Main Factors}

The annual and seasonal variation in the five factors on the Loess Plateau from 1985 to 2014 are shown in Figure 6, and the significance of the changing trend of each factor is tested based on M-K analysis.

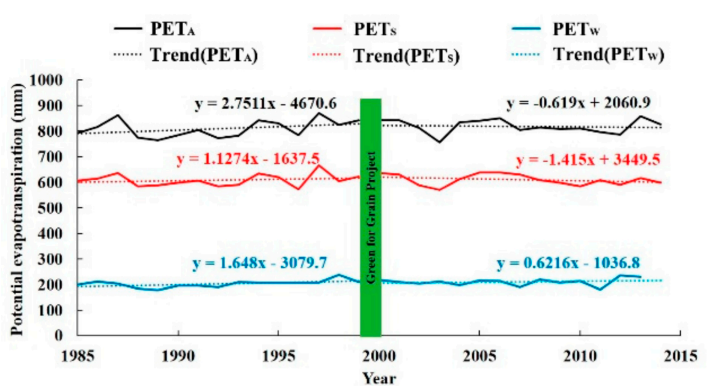

(a)PET

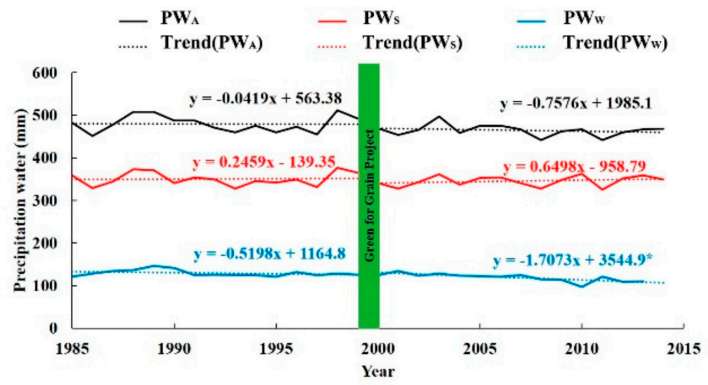

(c)PW

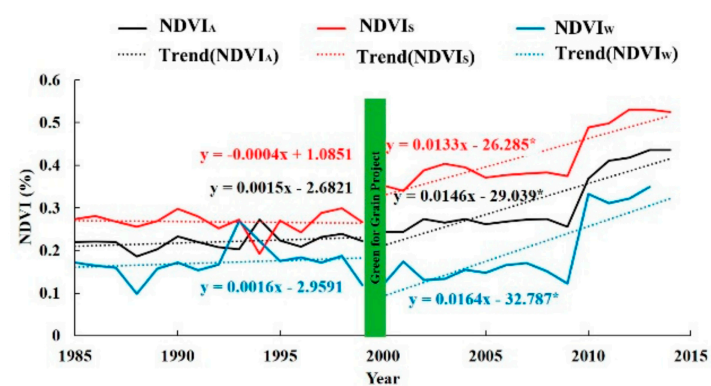

(b)NDVI

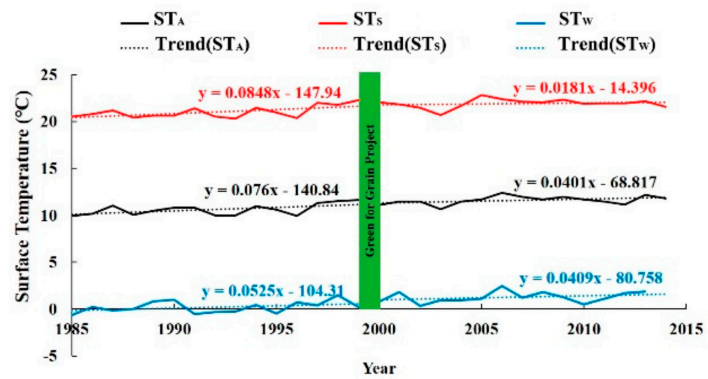

(d)ST

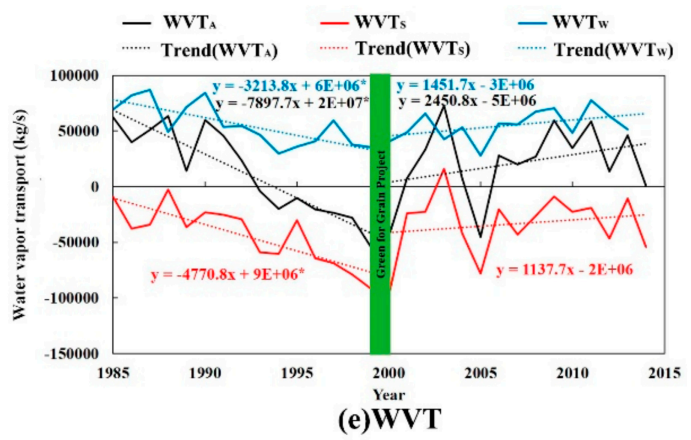

Figure 6. The annual and seasonal trend of five factors (a) PET, (b) NDVI, (c) PW, (d) ST, (e) WVT ("*" indicates that the trend is statistically significant at the $95 \%$ confidence level).

As shown in Figure 6, the $\mathrm{PET}_{\mathrm{A}}$ and $\mathrm{PET}_{\mathrm{S}}$ changed from the increase trend in Period I to the decrease trend in Period II, and the $\mathrm{PET}_{\mathrm{W}}$ increased all the time. The $\mathrm{NDVI}_{\mathrm{A}}$ and $\mathrm{NDVI}_{\mathrm{W}}$ in Period I showed a slight upward trend; moreover, in Period II, $\mathrm{NDVI}_{\mathrm{A}}$, $\mathrm{NDVI}_{S}, \mathrm{NDVI}_{\mathrm{W}}$ all showed an increasing trend with a $95 \%$ confidence level. It should be noted that the NDVI showed a gradually increasing trend from 2000 to 2003, but increased afforestation would increase transpiration and lead to water shortages; vegetation growth is restricted, which may be one of the reasons that NDVI showed a slightly decreasing between 2004 and 2006. After 2009, the NDVI gradually increased, which was mainly due 
to the surviving vegetation beginning to flourish after adapting to the local environment. Therefore, there may be a lag period for vegetation restoration. The $\mathrm{PW}_{\mathrm{A}}$ and $\mathrm{PW}_{\mathrm{W}}$ both showed a decrease trend before and after the GFGP, but PW $\mathrm{S}$ kept increasing. The ST showed an increasing trend, but the increase rate of ST in Period II was lower than that in Period I. The $\mathrm{WVT}_{\mathrm{A}}, \mathrm{WVT}_{\mathrm{S}}$, and $\mathrm{WVT}_{\mathrm{W}}$ showed a statistically significant downward trend with a 95\% confidence level in Period I, but increasing in Period II. Together, from the temporal trend of each factor, the PET, NDVI, and WVT changed before and after the GFGP.

\subsubsection{The Spatial Variability of the Main Factors}

To further analyze the spatial distribution and variation of each factor in Period I and Period II, the spatial distribution of each factor in the annual and seasonal scales and spatial difference between the two periods were mapped, respectively, in Figure 7a-c. It is worth noting that the WVT is the water vapor flux value of the entire Loess Plateau, which cannot present spatial distribution.

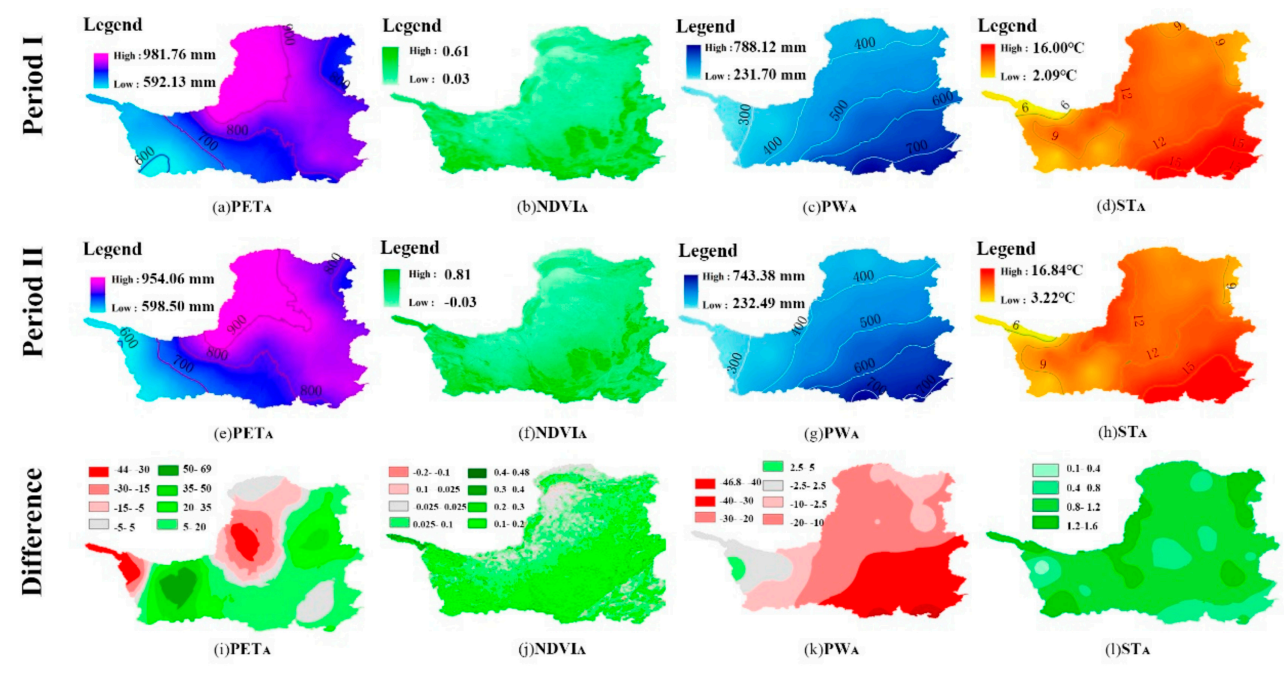

(a)

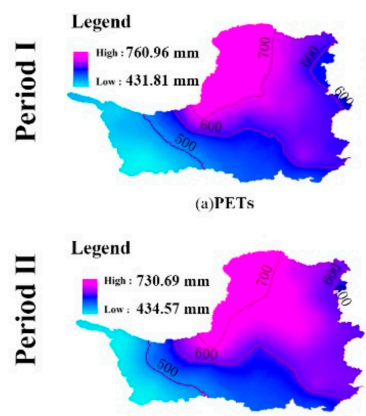

(e)PETS

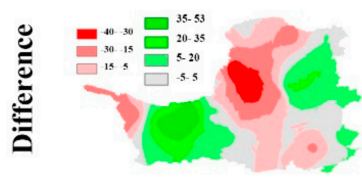

(i)PETs

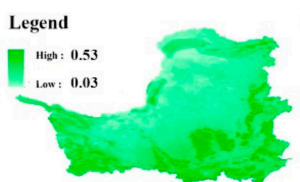

(b)NDVIs

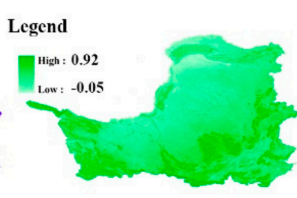

(f)NDVIs

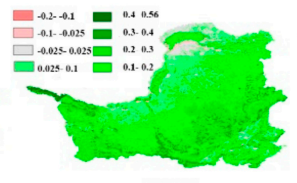

(j)NDVIs

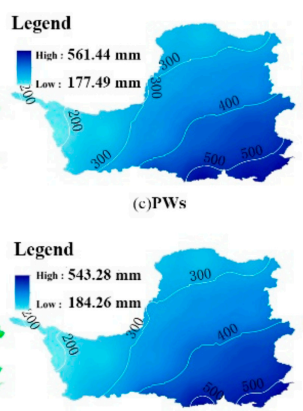

(g)PWs

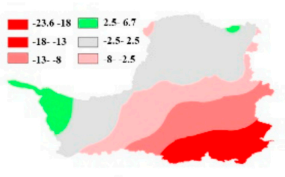

(k)PWs

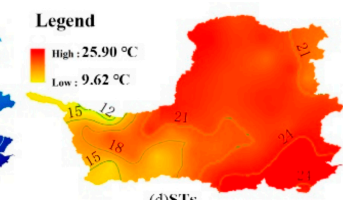

(d) $\mathrm{S}$ ! Legend

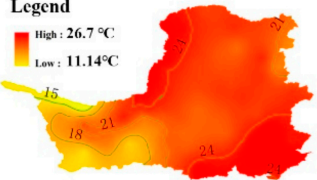

(h)STs

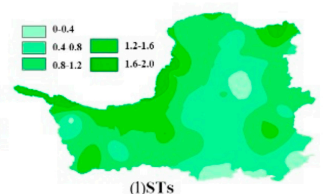

(b)

Figure 7. Cont. 


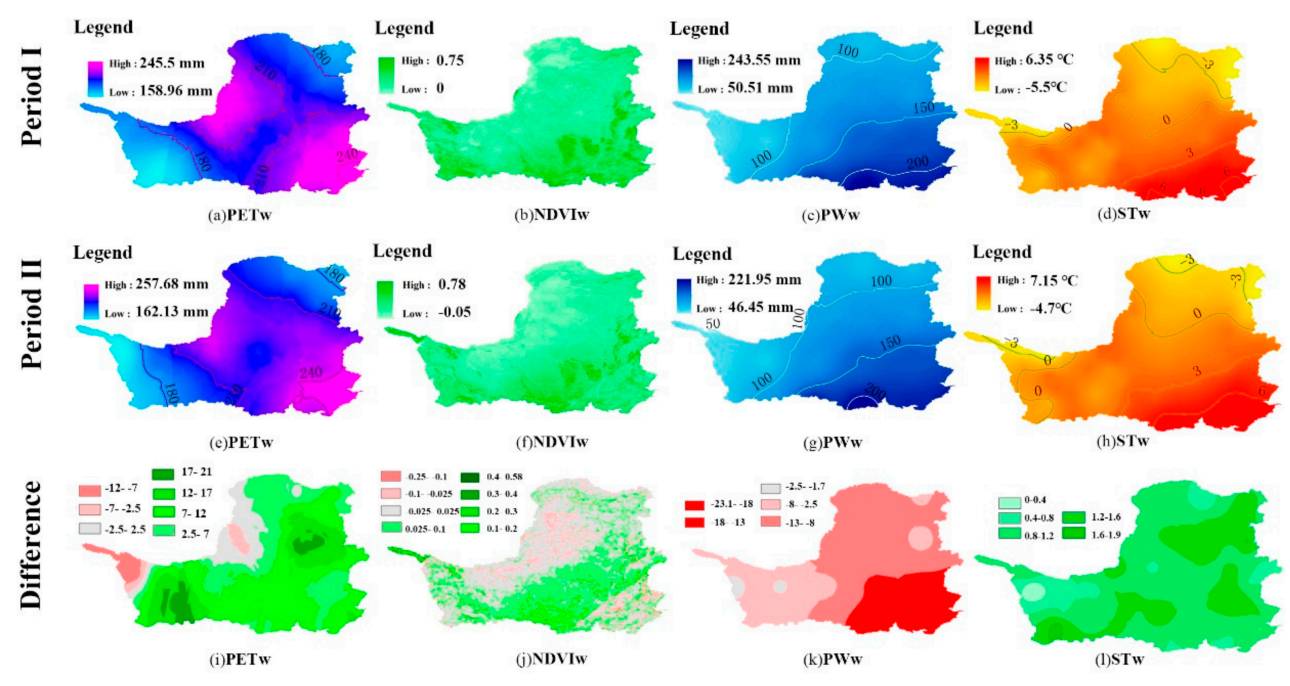

(c)

Figure 7. (a) The spatial distribution of the annual variation of factors. (b) The spatial distribution of the summer (4-9) variation of factors. (c) The spatial distribution of the winter (10-3) variation of factors.

As shown in Figure 7a-c, from the perspective of spatial distribution, the spatial distribution, NDVI, and PW of the annual, summer, and winter scales showed a decreasing trend from the southeast to northwest, similar to the spatial distribution of precipitation. The higher values of PET are distributed in the northwest, central, and southeast. The lower values of ST are distributed in the southwest. From the perspective of spatial variation, the NDVI in the southeast increased significantly in the annual, summer, and winter scales, similar to those of precipitation. At the same time, PET increased in the southwest and northeast, ST increased in the whole area, while PW decreased in the whole area. To sum up, NDVI was similar to precipitation in spatial distribution and variation. Meanwhile, PET, NDVI, and ST all increased after the GFGP.

\subsection{Identification of the Main Influencing Factors of Precipitation Change 4.3.1. Correlation Analysis}

This study drew scatter plots to analyze the correlation of precipitation and five factors before and after the GFGP, as shown in Figure 8. From the perspective of the annual and summer scales, the precipitation was positively correlated with PW and WVT, and negatively correlated with PET and ST. PW and WVT are water vapor factors, and the increase in water vapor had a promoting effect on the occurrence of precipitation. Moreover, NDVI was positively correlated with precipitation after the GFGP, and the correlation coefficient $r$ was 0.82 and 0.85 . This may be due to the increase in vegetation coverage having enhanced the regional water cycle and then increased the precipitation. In terms of winter, the precipitation was positively correlated with PW and WVT, and negatively correlated with other factors. The moisture sources of $\mathrm{PRE}_{\mathrm{W}}$ mainly come from atmospheric circulation. Therefore, with the decrease in PW and WVT, the winter precipitation will also decrease. In summary, we found that the five factors had an obvious linear correlation with precipitation through correlation analysis. Therefore, in the next part, the principal component regression analysis will be used to further quantify the relative influence degree of each factor to precipitation before and after the GFGP. 


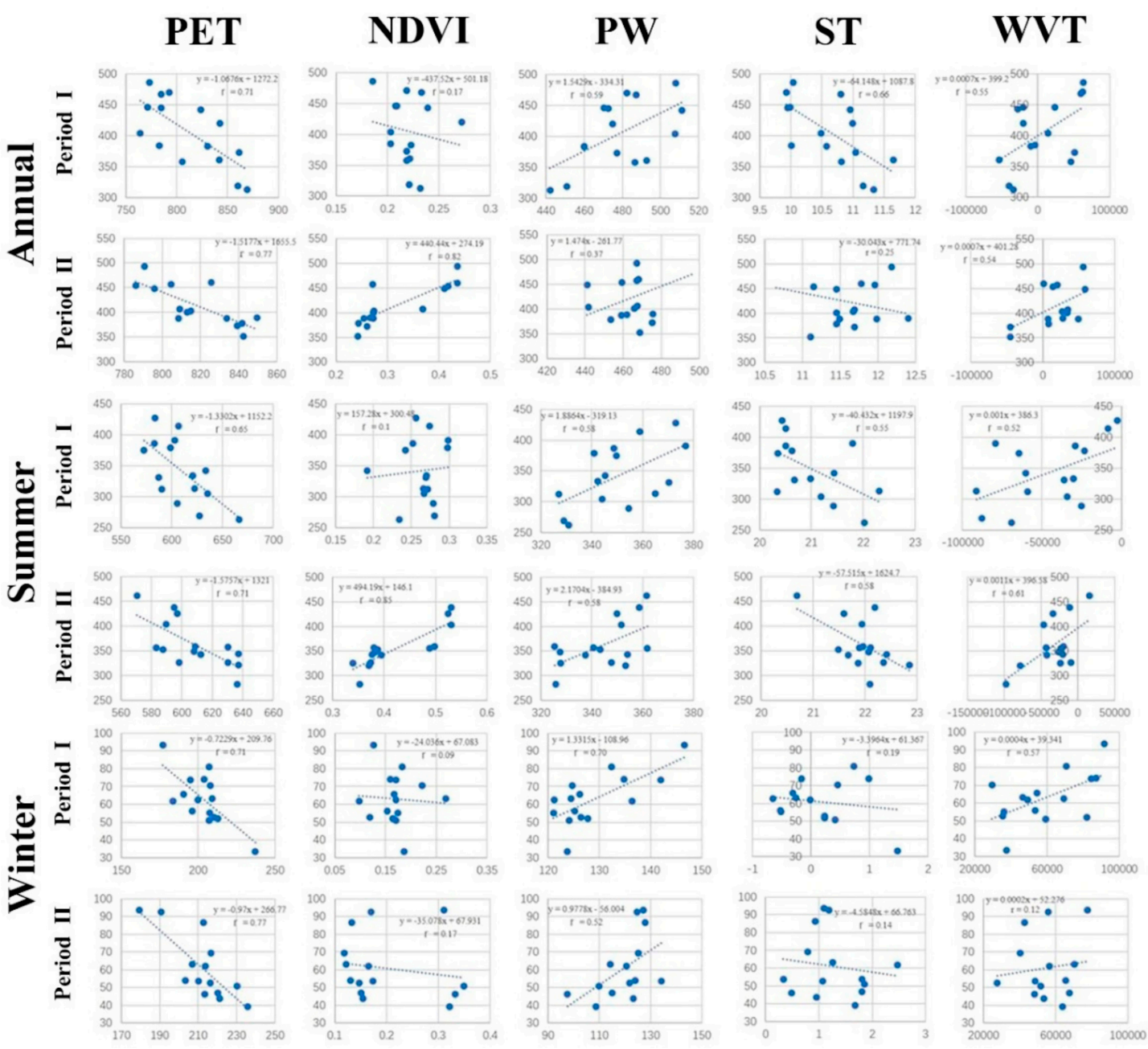

Figure 8. The correlation analysis of factors to precipitation before and after GFGP.

\subsubsection{The Relative Influence Degree of the Five Factors to Precipitation Change}

Based on the correlation of precipitation and main factors, we further calculated the influence degree of each factor to precipitation through principal component regression analysis. The extraction of principal components and evaluation parameters of the principal component regression analysis are shown in Table 2. We converted five original factors into four linearly uncorrelated variables, and the cumulative contribution rate was greater than $96 \%$. That is, the selected principal component could retain almost all the information of the original factors. At the same time, the significance test parameter (sig.) showed that all the regression models had passed the significance test $(\alpha=0.05)$, and the adjusted $R^{2}$ was more than 0.39 . In general, the principal component regression analysis can be used to measure the impact of factors on precipitation.

Table 2. The extraction of principal components and evaluation parameters.

\begin{tabular}{|c|c|c|c|c|c|}
\hline \multicolumn{2}{|c|}{ Scale } & Cumulative Contribution Rate/\% & Number of Principal Components & Adjusted-R ${ }^{2}$ & Sig. \\
\hline \multirow[b]{2}{*}{ Annual } & Period I & 98 & 4 & 0.50 & 0.026 \\
\hline & Period II & 98 & 4 & 0.45 & 0.038 \\
\hline \multirow{2}{*}{ Summer } & Period I & 98 & 4 & 0.67 & 0.004 \\
\hline & Period II & 96 & 4 & 0.67 & 0.003 \\
\hline \multirow{2}{*}{ Winter } & Period I & 96 & 4 & 0.58 & 0.011 \\
\hline & Period II & 96 & 4 & 0.39 & 0.048 \\
\hline
\end{tabular}


The influence degree of factors to precipitation before and after the GFGP is shown in Figure 9. In terms of annual scale, PW had the greatest influence on precipitation in Period I, with a relative influence degree of $41.33 \%$; in Period II, NDVI and PW had the greatest impact on precipitation, with relative influence degrees of 30.18 and $26.63 \%$, respectively. In terms of the summer season, PET and PW influenced precipitation most in Period I, with relative influence degrees of $32.17 \%$ and $22.63 \%$, respectively; while in Period II, NDVI and PW had the greatest impact on precipitation, with relative influence degrees of 31.37 and $24.26 \%$, respectively. In terms of the winter season, WVT and PW had the greatest influence on precipitation in Period I, with relative influence degrees of $41.21 \%$ and $25.50 \%$, respectively; while in Period II, PW and PET had the greatest impact on precipitation, with relative influence degrees of $30.13 \%$ and $27.64 \%$, respectively.

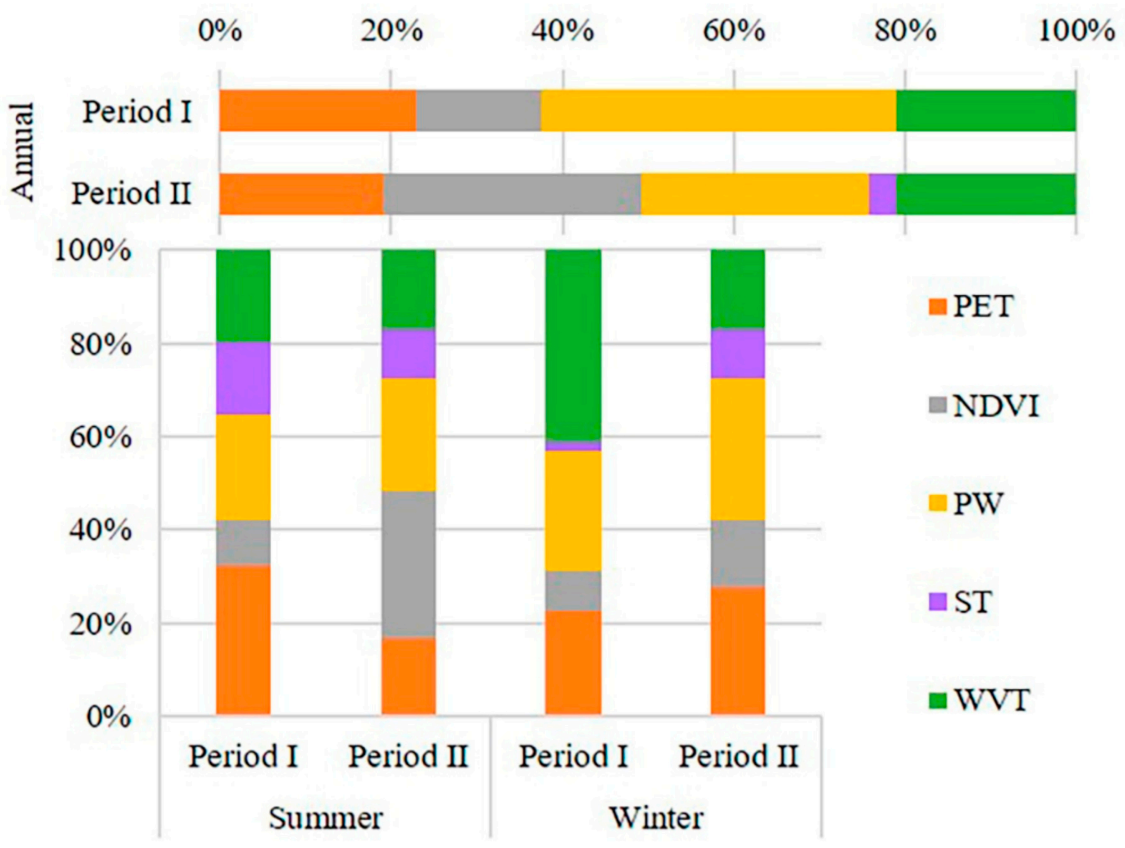

Figure 9. The influence degree of factors to precipitation before and after GFGP.

Based on the results of statistical analysis, we compared the main factors of precipitation before and after the GFGP and found that, in terms of annual scale, the relative influence degree of NDVI to precipitation changed significantly from $14.80 \%$ before the GFGP to $30.18 \%$ after the GFGP. In terms of summer scale, the relative influence degree of NDVI to precipitation increased significantly from $9.78 \%$ before the GFGP to $31.37 \%$ after the GFGP. Therefore, we speculate that vegetation restoration had a certain promoting effect on precipitation. The substantial increase in vegetation coverage in summer had increased the water consumption through transpiration and evaporation; then, the regional water consumption increased significantly along with the accelerated local water cycle, which might lead to the significant increase in the precipitation. PW and PET were the main factors affecting PRE $_{\mathrm{W}}$ after the GFGP. According to the scatter plot of Figure 8, PRE was positively correlated with PW and negatively correlated with PET; PW decreased and PET increased during Period II, which jointly leads to the decrease in PRE ${ }_{W}$. In summary, with the increase in precipitation in recent years, the Loess Plateau presented a trend of warming and wetting, and we speculated that this might be due to global climate change on the one hand and the changes in the local climate brought by vegetation restoration on the other hand. 


\section{Discussion}

\subsection{Identification of Main Factors in Sub-Regions}

After the implementation of the GFGP in the Loess Plateau in 1999, the vegetation coverage in the central and western part of the loess Plateau increased significantly [9], while the NDVI in the northwest part obviously did not increase [48]. The vegetation restoration speed was uneven in spatial distribution. Therefore, to further analyze the contribution rate of each factor to precipitation in different regions of the Loess Plateau, the study area was divided into 22 sub-regions according to the $2.5^{\circ} \times 2.5$ grid, and the most influence factors of each sub-region were identified based on the principal component regression method. The results are shown in Figure 10.

\section{Period I}

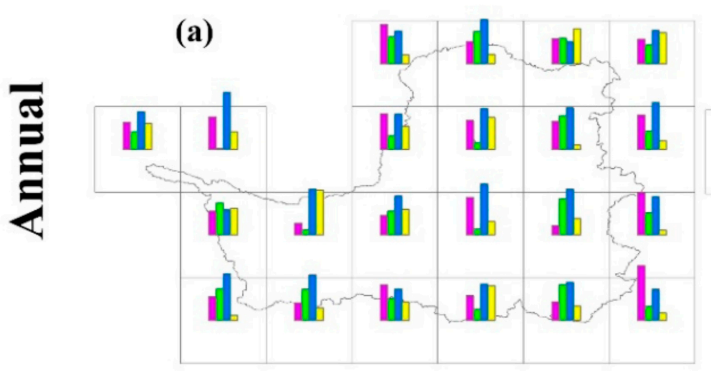

(c)

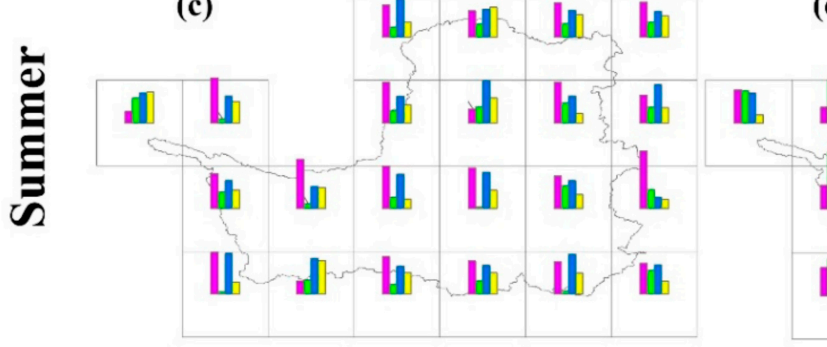

(e)

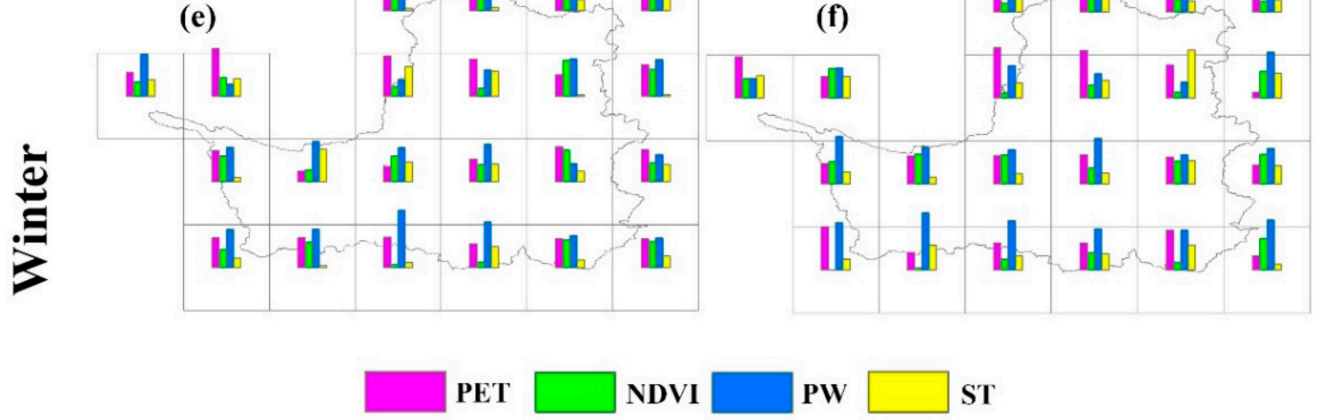

(b)

\section{Period II}

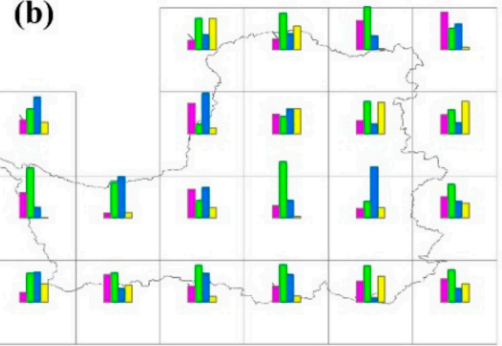

(d)

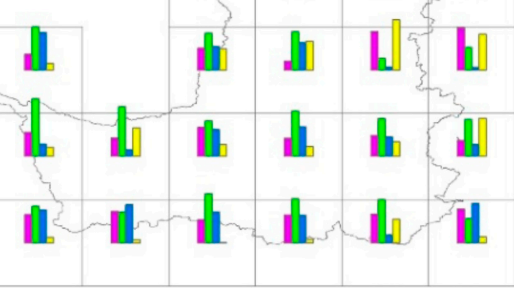

(f)

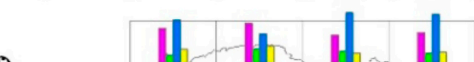

Figure 10. The influence degree of factors to annual precipitation in Period I (a) and Period II (b) in 22 subregions. The influence degree of factors to summer precipitation in Period I (c) and Period II (d). The influence degree of factors to winter precipitation in Period I (e) and Period II (f).

The influence degree of factors to $\mathrm{PRE}_{\mathrm{A}}$ are shown in Figure 10a,b. PW was the main influencing factor in $63.6 \%$ of the regions, with an average relative influence degree of $36.2 \%$ in Period I. During Period II, NDVI was the main influencing factor in $59.1 \%$ of the regions, with an average relative influence degree of $35.5 \%$. In the central area, the relative influence degree of NDVI to precipitation was higher than that before the GFGP. The main influencing factors for the PRE $E_{S}$ are shown in Figure 10c,d; during Period I, PET was the main influencing factor in $68.2 \%$ of the regions, with an average relative influence degree of $35.1 \%$. In Period II, the main influencing factor in $72.7 \%$ of the regions was NDVI, with an average relative influence degree of $36.7 \%$, and which had increased significantly in 
the central and eastern regions. The influence degree of factors of the $\mathrm{PRE}_{W}$ are shown in Figure 10e,f. During Period I, PW was the main influence factor in $68.2 \%$ of the regions, with an average influence degree of $34.3 \%$. During Period II, the main influencing factor was PW, with an average relative influence degree of $38.1 \%$.

From the results, this study found that NDVI was the main influencing factor to the annual and summer precipitation after the GFGP. The mechanism may be that, with the increase in vegetation coverage, the water consumption of vegetation and evapotranspiration of soil water increase. The regional water cycle accelerates, and the local microclimate has improved, which has a positive feedback effect on precipitation $[49,50]$. As precipitation increases, the water demand for vegetation growth is satisfied. Therefore, the vegetation coverage is improved, which means NDVI and precipitation have a close reciprocal relationship [50,51]. The winter precipitation was mainly affected by PW and PET. In winter, the source of water vapor was affected by atmospheric circulation, and the occurrence of precipitation was also greatly affected by climate.

\subsection{The Comparison between Our Findings and Those of the Previous Studies}

To analyze the change in precipitation before and after the implementation of the Grain for Green Project (GFGP) in the Loess Plateau, we found that precipitation had increased significantly after the GFGP. This conclusion is consistent with previous research with respect to climatic variables. For example, Zhao et al. [10] analyzed the spatiotemporal evolution of drought in the Loess Plateau from 1998 to 2014 based on TRMM (The Tropical Rainfall Measuring Mission) multi-satellite precipitation data. The results showed that precipitation on the Loess Plateau increased significantly from 1998 to 2014, and that drought severity in the Loess Plateau was a declining trend; Gao et al. [2] pointed out that the precipitation increased significantly from 1990 to 2014 in the Loess Plateau; Cheng et al. [14] analyzed the variability in average precipitation from 77 meteorological stations during 1960-2011, and found that the precipitation in the Loess Plateau had a decreasing trend before 2000, but an increasing trend after 2000. However, Tang et al. [52] made an analysis of the spatial-temporal changes of precipitation on the Loess Plateau based on 170 meteorological data. The result pointed out that the precipitation showed a decreasing trend during 1965-2014. The conflict between this result and our study may be due to the different data sources of precipitation, and more importantly, the different research period selected; Tang ignored the increasing trend of precipitation after the implementation of the GFGP.

In this study, we found that vegetation restoration had a great influence on precipitation after the GFGP, and speculated that vegetation restoration improves the local microclimate and promotes precipitation; the previous related studies have similar conclusions to ours. For example, Gao et al. [2] found that during 1990-2014, NDVI, precipitation, and AET have increasing trends; moreover, AET has a similar distribution to precipitation. Regional precipitation likely contributes to an increase in AET, and the AET increase may also influence the precipitation. Li et al. [9] evaluated the changes in NDVI in the Loess Plateau around the past 30 years and concluded that the study area became warmer, more humid, and in which drought decreased after the implementation of the GFGP. NDVI in the southeast of the Loess Plateau was mainly affected by precipitation, and the change in NDVI also had a feedback effect on regional precipitation. Wang et al. [48] studied the spatiotemporal changes of soil moisture content (SMC) and vegetation in the Loess Plateau, as well as the impact of precipitation on soil moisture content (SMC) and vegetation coverage. The results showed a significant correlation between annual precipitation and vegetation coverage during 2000 to 2015 in the northeast and west of the Loess Plateau. In summary, this study quantitatively analyzed the factors affecting precipitation on the Loess Plateau, and the results are basically consistent with previous findings. 


\section{Conclusions}

Since the implementation of the Grain for Green Project (GFGP) in 1999, precipitation has increased significantly and the region features a warmer and wetter climate. In order to quantitatively analyze the impact of vegetation restoration on precipitation, this study mainly analyzed the temporal and spatial variation of precipitation and the potential influencing factors before and after the GFGP in the Loess Plateau. This study compared the influence degree of NDVI to precipitation before and after the GFGP, found that vegetation restoration had a great influence on precipitation after the GFGP, and speculated that vegetation recovery may have a positive feedback effect on regional precipitation. The main findings are concluded as follows:

(1) Precipitation in the Loess Plateau increased significantly after the GFGP. Before the GFGP, precipitation at $72.6 \%$ of all stations was in a decreasing trend, while $84.5 \%$ of stations showed an increasing trend after the GFGP and in the central and north stations at a $90 \%$ confidence level.

(2) With the implementation of the GFGP and climate change, the annual precipitation $\left(\mathrm{PRE}_{\mathrm{A}}\right)$ increased at a rate of $4.96 \mathrm{~mm} / \mathrm{a}$, and the summer precipitation $\left(\mathrm{PRE}_{\mathrm{S}}\right)$ increased at a rate of $5.63 \mathrm{~mm} / \mathrm{a}$. The $\mathrm{PRE}_{\mathrm{A}}$ and $\mathrm{PRE}_{\mathrm{S}}$ both showed increasing trends with a $95 \%$ confidence level. The spatial distribution of precipitation decreased from the southeast to northwest. After the GFGP, the $\mathrm{PRE}_{\mathrm{A}}$ and $\mathrm{PRE}_{\mathrm{S}}$ in the southeast increased significantly by around $20-50 \mathrm{~mm}$, while the change in the winter precipitation $\left(\mathrm{PRE}_{\mathrm{W}}\right)$ was not significant.

(3) The influence degree of NDVI on regional precipitation increased after the GFGP. Specifically, the annual precipitation $\left(\mathrm{PRE}_{\mathrm{A}}\right)$ and the summer precipitation $\left(\mathrm{PRE}_{\mathrm{S}}\right)$ were mainly influenced by NDVI, with relative influence degrees of $30.00 \%$ and $30.62 \%$, respectively, and the PW was the second influencing factor. The winter precipitation $\left(\mathrm{PRE}_{\mathrm{W}}\right)$ was more influenced by PW and PET, with relative influence degrees of $33.03 \%$ and $27.80 \%$, respectively. According to the above results, we speculate that the trend of warming and wetting of the Loess Plateau is not only closely related to global climate change on the one hand, but also significantly affected by the changes in the local climate brought by vegetation restoration on the other.

(4) In this study, the implementation of the Grain for Green Project (GFGP) was used as the time node to analyze the contribution rates of five main factors to precipitation changes. However, statistical methods were used to analyze the feedback of vegetation restoration to precipitation, which makes the interaction mechanism between them difficult to explain. Therefore, it should be necessary to further study the ecological and hydrological processes in this region.

Author Contributions: Research design and organization, X.G.; data processing and writingoriginal draft preparation, J.W.; draft modification, writing-review, M.S.; supervision and funding acquisition, X.Z. and Y.Z. All authors have read and agreed to the published version of the manuscript.

Funding: This research was funded by the Technological Innovation Project of Shaanxi Academy of Forestry (SXLk2020-0304).

Institutional Review Board Statement: Not applicable.

Informed Consent Statement: Not applicable.

Data Availability Statement: The data presented in this study are available on reasonable request from the corresponding author.

Acknowledgments: This study is supported by the Technological Innovation Project of Shaanxi Academy of Forestry (SXLk2020-0304) and the National Key Research and Development Program of China (2018YFF0215702). The research kindly thanks the data support from the "National Earth System Science Data Center, National Science \& Technology Infrastructure of China. (http:/ /www.geodata.cn)". Thanks are also extended to anonymous reviewers for their insights and recommendations.

Conflicts of Interest: The authors declare no conflict of interest. 


\section{References}

1. Li, J.; Peng, S.; Li, Z. Detecting and attributing vegetation changes on China's Loess Plateau. Agr. Forest Meteorol. 2017, 247, 260-270. [CrossRef]

2. Gao, X.; Sun, M.; Zhao, Q.; Wu, P.; Zhao, X.; Pan, W.; Wang, Y. Actual ET modelling based on the Budyko framework and the sustainability of vegetation water use in the loess plateau. Sci. Total Environ. 2017, 579, 1550-1559. [CrossRef] [PubMed]

3. Liang, K.; Liu, C.; Liu, X.; Song, X. Impacts of climate variability and human activity on streamflow decrease in a sediment concentrated region in the Middle Yellow River. Stoch. Environ. Res. Risk A 2013, 27, 1741-1749. [CrossRef]

4. Feng, X.; Fu, B.; Piao, S.; Wang, S.; Ciais, P.; Zeng, Z.; Lu, Y.; Zeng, Y.; Li, Y.; Jiang, X.; et al. Revegetation in China's Loess Plateau is approaching sustainable water resource limits. Nat. Clim. Chang. 2016, 6, 1019-1022. [CrossRef]

5. Wang, S.; Fu, B.; Piao, S.; Lu, Y.; Ciais, P.; Feng, X.; Wang, Y. Reduced sediment transport in the Yellow River due to anthropogenic changes. Nat. Geosci. 2016, 9, 38-41. [CrossRef]

6. Yang, X.; Sun, W.; Li, P.; Mu, X.; Gao, P.; Zhao, G. Reduced sediment transport in the Chinese Loess Plateau due to climate change and human activities. Sci. Total Environ. 2018, 642, 591-600. [CrossRef] [PubMed]

7. Deng, L.; Liu, G.; Shangguan, Z. Land-use conversion and changing soil carbon stocks in China's 'Grain-for-Green' Program: A synthesis. Glob. Chang. Biol. 2014, 20, 3544-3556. [CrossRef]

8. Yan, L. Characteristics of temperature and precipitation on the Loess Plateau from1961 to 2014. J. Earth Environ. 2015, 6, 276-282. (In Chinese) [CrossRef]

9. Li, G.; Sun, S.; Han, J.; Yan, J.; Liu, W.; Wei, Y.; Lu, N.; Sun, Y. Impacts of Chinese Grain for Green program and climate change on vegetation in the Loess Plateau during 1982-2015. Sci. Total Environ. 2019, 660, 177-187. [CrossRef]

10. Zhao, Q.; Chen, Q.; Jiao, M.; Wu, P.; Gao, X.; Ma, M.; Hong, Y. The Temporal-Spatial Characteristics of Drought in the Loess Plateau Using the Remote-Sensed TRMM Precipitation Data from 1998 to 2014. Remote Sens. 2018, 10, 838. [CrossRef]

11. Wang, Q.; Fan, X.; Qin, Z.; Wang, Q. Change trends of temperature and precipitation in the Loess Plateau Region of China, 1961-2010. Glob. Planet Chang. 2012, 138-147. [CrossRef]

12. Yilmaz, A.G.; Hossain, I.; Perera, B.J. Effect of climate change and variability on extreme rainfall intensity-frequency-duration relationships: A case study of Melbourne. Hydrol. Earth Syst. Sci. 2014, 18, 4065-4076. [CrossRef]

13. Onyutha, C.; Willems, P. Influence of spatial and temporal scales on statistical analyses of rainfall variability in the River Nile basin. Dynam. Atmos. Oceans 2017, 77, 26-42. [CrossRef]

14. Cheng, N.; He, H.; Lu, Y.; Jing, Z. Spatial-temporal Dynamic Characteristics of Precipitation in the Loess Plateau, China for Recent 52 Years. J. Shandong Agric. Univ. (Natural Science Edition) 2016, 47, 388-392. (In Chinese) [CrossRef]

15. Zheng, Y.; He, Y.; Chen, X. Spatiotemporal pattern of precipitation concentration and its possible causes in the Pearl River basin, China. J. Clean Prod. 2017, 161, 1020-1031. [CrossRef]

16. Wang, Y.; Lv, S. Sensitivity Analysis of the Response of Precipitation to Climate Change over China Loess Plateau. J. Glaciol. Geocryol. 2008, 30, 43-51. (In Chinese)

17. Choudhury, G.; Tyagi, B.; Singh, J.; Sarangi, C.; Tripathi, S.N. Aerosol-orography-precipitation-A critical assessment. Atmos Environ. 2019, 214, 1-19. [CrossRef]

18. Pan, B.; Yao, Z.; Wang, M.; Pan, H.; Bu, L.; Kumar, K.R.; Gao, H.; Huang, X. Evaluation and utilization of CloudSat and CALIPSO data to analyze the impact of dust aerosol on the microphysical properties of cirrus over the Tibetan Plateau. Adv. Space Res. 2019, 63, 2-15. [CrossRef]

19. Martens, H.; Martens, M. Modified Jack-knife estimation of parameter uncertainty in bilinear modelling by partial least squares regression (PLSR). Food Qual. Prefer. 2000, 11, 5-16. [CrossRef]

20. Fang, S.; Jia, R.; Tu, W.; Sun, Z. Assessing Factors Driving the Change of Irrigation Water-Use Efficiency in China Based on Geographical Features. Water 2017, 9, 759. [CrossRef]

21. Chen, M.; Luo, Y.; Shen, Y.; Han, Z.; Cui, Y. Driving force analysis of irrigation water consumption using principal component regression analysis. Agr. Water Manage. 2020, 234, 106089. [CrossRef]

22. Tang, Y.; Feng, F.; Guo, Z.; Feng, W.; Li, Z.; Wang, J.; Sun, Q.; Ma, H.; Li, Y. Integrating principal component analysis with statistically-based models for analysis of causal factors and landslide susceptibility mapping: A comparative study from the loess plateau area in Shanxi (China). Clean Prod. 2020. [CrossRef]

23. Zeng, Y.; Yang, X.; Fang, N.; Shi, Z. Large-scale afforestation significantly increases permanent surface water in China's vegetation restoration regions. Agr. Forest Meteorol. 2020, 290, 108001. [CrossRef]

24. Chen, L.; Wei, W.; Fu, B.; Lu, Y. Soil and water conservation on the Loess Plateau in China: Review and perspective. Prog. Phys. Geog. 2007, 31, 389-403. [CrossRef]

25. Li, Z.; Zheng, F.; Liu, W.; Jiang, D. Spatially downscaling GCMs outputs to project changes in extreme precipitation and temperature events on the Loess Plateau of China during the 21st Century. Global Planet. Chang. 2012, 82, 65-73. [CrossRef]

26. Gocic, M.; Trajkovic, S. Analysis of precipitation and drought data in Serbia over the period 1980-2010. J. Hydrol. 2013, 494, 32-42. [CrossRef]

27. Guclu, Y.S. Improved visualization for trend analysis by comparing with classical Mann-Kendall test and ITA. J. Hydrol. 2020, 584, 124674. [CrossRef]

28. Kendziorski, C.M.; Bassingthwaighte, J.B.; Tonellato, P.J. Evaluating maximum likelihood estimation methods to determine the Hurst coefficient. Physica A 1999, 273, 439-451. [CrossRef] 
29. Tong, S.; Lai, Q.; Zhang, J.; Bao, Y.; Lusi, A.; Ma, Q.; Li, X.; Zhang, F. Spatiotemporal drought variability on the Mongolian Plateau from 1980-2014 based on the SPEI-PM, intensity analysis and Hurst exponent. Sci. Total Environ. 2017, 15, 1557-1565. [CrossRef]

30. Xie, S.; Mo, X.; Hu, S.; Liu, S. Contributions of climate change, elevated atmospheric $\mathrm{CO}_{2}$ and human activities to ET and GPP trends in the Three-North Region of China. Agr. Forest Meteorol. 2020, 295, 108183. [CrossRef]

31. Zhang, C.; Wang, X.; Li, J.; Hua, T. Identifying the effect of climate change on desertification in northern China via trend analysis of potential evapotranspiration and precipitation. Ecol. Indic. 2020, 112, 106141. [CrossRef]

32. Jin, K.; Wang, F.; Li, P. Responses of Vegetation Cover to Environmental Change in Large Cities of China. Sustainability 2018, 10, 270. [CrossRef]

33. Wang, H.; He, J. Temporal and Spatial Evolution Features of Precipitable Water in China during a Recent 65-Year Period (1951-2015). Adv. Meteorol. 2017, 1-11. [CrossRef]

34. Xu, X.; Lu, C.; Shi, X.; Gao, S. World water tower: An atmospheric perspective. Geophys. Res. Lett. 2008, 35. [CrossRef]

35. Zhang, B.; Wu, P.; Zhao, X.; Wang, Y.; Gao, X. Changes in vegetation condition in areas with different gradients (1980-2010) on the Loess Plateau, China. Environ. Earth Sci. 2013, 68, 2427-2438. [CrossRef]

36. Zhao, T.; Wang, J.; Dai, A. Evaluation of atmospheric precipitable water from reanalysis products using homogenized radiosonde observations over China. J. Geophys. Res. 2015, 120. [CrossRef]

37. Li, L.; Zha, Y.; Wang, R. Relationship of surface urban heat island with air temperature and precipitation in global large cities. Ecol. Indic. 2020, 117, 106683. [CrossRef]

38. Huang, D.; Yan, P.; Xiao, X.; Zhu, J.; Tang, X.; Huang, A.; Cheng, J. The tri-pole relation among daily mean temperature, atmospheric moisture and precipitation intensity over China. Glob. Planet Chang. 2019, 179, 1-9. [CrossRef]

39. Jin, K.; Wang, F.; Zong, Q.; Qin, P.; Liu, C. Impact of variations in vegetation on surface air temperature change over the Chinese Loess Plateau. Sci. Total Environ. 2020. [CrossRef]

40. Yao, J.; Chen, Y.; Zhao, Y.; Guan, X.; Mao, W.; Yang, L. Climatic and associated atmospheric water cycle changes over the Xinjiang, China. J. Hydrol. 2020, 585, 124823. [CrossRef]

41. Liu, R. The Calculation and Analysis of Atmospheric Precipitable Water and Water Vapor Transportation and Net Income in Xinjiang. Master's Thesis, Xinjiang Normal University, Xinjiang, China, 2009. (In Chinese).

42. Wu, Y.; Shen, Y.; Li, B.L. Possible physical mechanism of water vapor transport over Tarim River Basin. Ecol. Complex. 2012, 9, 63-70. [CrossRef]

43. Shi, Y. A Study on the Spatial-Temporal Distributions of Areal Precipitation and Water Vapor over Xinjiang. Ph.D. Thesis, Nanjing University of Information Science \& Technology, Nanjing, China, 2009. (In Chinese).

44. Pandžic, K.; Trninic, D. Principal component analysis of a river basin discharge and precipitation anomaly fields associated with the global circulation. J. Hydrol. 1992, 132, 343-360. [CrossRef]

45. Nagel, J.B.; Rieckermann, J.; Sudret, B. Principal component analysis and sparse polynomial chaos expansions for global sensitivity analysis and model calibration: Application to urban drainage simulation. Reliab. Eng. Syst. Safe 2020, 195, 106737. [CrossRef]

46. Voukantsis, D.; Karatzas, K.; Kukkonen, J.; Räsänen, T.; Karppinen, A.; Kolehmainen, M. Intercomparison of air quality data using principal component analysis, and forecasting of PM 10 and PM 2.5 concentrations using artificial neural networks, in Thessaloniki and Helsinki. Sci. Total Environ. 2011, 409, 1266-1276. [CrossRef] [PubMed]

47. Arjo, D. Statistical Models: Theory and Practice. Technometrics 2009, 48, 315. [CrossRef]

48. Wang, X.; Wang, B.; Xu, X.; Liu, T.; Duan, Y.; Zhao, Y. Spatial and temporal variations in surface soil moisture and vegetation cover in the Loess Plateau from 2000 to 2015. Ecol. Indic. 2018, 95, 320-330. [CrossRef]

49. Zhang, D.; Huang, J.; Guan, X.; Chen, B.; Zhang, L. Long-term trends of precipitable water and precipitation over the Tibetan Plateau derived from satellite and surface measurements. J. Quant. Spectrosc. Radiat. Transf. 2013, 122, 64-71. [CrossRef]

50. Sun, W.; Song, X.; Mu, X.; Gao, P.; Wang, F.; Zhao, G. Spatiotemporal vegetation cover variations associated with climate change and ecological restoration in the Loess Plateau. Agr. Forest Meteorol. 2015, 2015, 87-99. [CrossRef]

51. Xin, Z.; Xu, J.; Zheng, W. Spatiotemporal variations of vegetation cover on the Chinese Loess Plateau (1981-2006): Impacts of climate changes and human activities. Sci. China Ser. D 2008, 51, 67-78. [CrossRef]

52. Tang, X.; Miao, C.; Xi, Y.; Duan, Q.; Lei, X.; Li, H. Analysis of precipitation characteristics on the loess plateau between 1965 and 2014, based on high-density gauge observations. Atmos. Res. 2018, 213, 264-274. [CrossRef] 